\title{
Transport corridors and their wider economic benefits: A quantitative review of the literature
}

\author{
Mark Roberts $^{1}$ (D) | Martin Melecky ${ }^{2,3}$ | Théophile Bougna ${ }^{4}$ \\ Yan (Sarah) $\mathrm{Xu}^{5}$
}

\footnotetext{
${ }^{1}$ The World Bank, Singapore, Singapore

${ }^{2}$ The World Bank, Washington, District of Columbia

${ }^{3}$ Faculty of Economics, The Technical University of Ostrava, Ostrava, Czech Republic

${ }^{4}$ The World Bank, Washington, District of Columbia

${ }^{5}$ Harvard Kennedy School, Cambridge, Massachusetts

\section{Correspondence}

Mark Roberts, The World Bank, Singapore Office, 10 Marina Boulevard, Singapore 018983, Singapore.

Email: mroberts1@worldbank.org
}

\begin{abstract}
Transport corridors can generate both wider economic benefits (WEBs) and costs through their effects on diverse development outcomes. To advance understanding of how corridors could generate WEBs, this paper undertakes a quantitative review and meta-analysis of the literature that estimates the impacts of large transport infrastructure projects. The analysis finds that characteristics of individual studies and the design of the transport infrastructure influence estimated benefits. It also shows that, on average, while corridor interventions tend to benefit economic welfare and equity, they often detrimentally impact the environment. To mitigate trade-offs, policymakers can consider using complementary interventions.

KEYWORDS

large-scale infrastructure investments, meta-analysis, transport corridors

JEL CLASSIFICATION

F15; H54; R12; R40
\end{abstract}

\section{1 | INTRODUCTION}

Current initiatives and proposals to build transport corridors could demand trillions of dollars, vastly exceeding the capacity of public finances. By reducing transport costs, such initiatives typically aim to unleash efficiencies in regional and transregional trade. But beyond savings of travel time and vehicle operating costs (VOCs), these initiatives also strive to generate net benefits for firms and households stemming from the increased economic opportunities that transport corridors could generate (ADB, DFID, JICA, \& WB, 2018). However, to help realize these benefits, national governments, the private sector, and the global development community need clear 
economic thinking on how to prioritize investment proposals for large transport projects and a proper methodology for project appraisals. Without such a methodology, these investments run the risk of uncoordinated efforts resulting in missed opportunities; of squandering limited public resources that could have been used, for instance, to improve education and health; of geopolitical considerations prevailing over economic prospects; and of possible misunderstandings between governments and among international organizations.

In parallel with rising interest among policymakers in appraising and prioritizing transport corridors, there has been a surge of academic interest in empirically evaluating the economic, social, and environmental impacts of large transport infrastructure projects (Berg, Deichmann, Liu, \& Selod, 2017; Laird \& Venables, 2017; Redding \& Turner, 2014). This surge has, at least partly, been driven by improved techniques for rigorously evaluating the economic impacts of these investments, as well as recently completed large-scale investments in transportation networks by countries such as China and India. The academic interest covers both these recent investments as well as historical large-scale investments, such as those of the United States in its railway network in the mid-1800s and of the British colonial authorities in the construction of the colonial Indian railway network in the late 19th and early 20th centuries. Recent studies also cover investments at a variety of scales, ranging from evaluating the impacts of individual links within either a pre-existing or a new system to evaluating the impacts of an entire national or even continental system. Some of these investments may not adhere to what are usually deemed corridor investments. Nevertheless, the large academic literature estimating the impacts of large-scale transport investments has the potential to inform policymakers' thinking on corridors and help develop a comprehensive methodology for appraising corridor projects.

This paper provides a rigorous review of the empirical literature estimating the impacts of large transport investments. In doing so, it aims to improve understanding of the multiple, and potentially varied, impacts of transport corridor investments. This includes enhancing understanding of the potential trade-offs that the investments can generate between different development outcomes, between different localities, and between different sets of economic actors. The review also informs policy thinking about the types of complementary policies and institutions that may be needed for wider economic benefits (WEBs) - that is, benefits that extend beyond savings in travel time and VOCs-of corridors to materialize. Ultimately, the aim is to inform thinking on what may constitute a socially optimal "corridor package"-defined as a set of interventions that extends beyond the investment in the trunk transport infrastructure to include policies and institutions that amplify the net economic benefits of such infrastructure.

In reviewing the literature and thinking about the wider economic impacts of transport corridors, our interest is not so much in the immediate outcomes such as travel time and VOC savings that remain the focus of most transport project cost-benefit analyses (CBA). ${ }^{1}$ Although their importance should not be dismissed and their accurate measurement remains an issue for CBA, these savings are unable to capture the full economic benefits of a transport project in anything other than a hypothetical world of perfectly competitive and complete markets (Vickerman, 2007). ${ }^{2}$ Rather, our interest is in the wider economic impacts of large transport projects, which include impacts on development outcomes such as economic welfare (monetary measures of well-being such as income, wages, and consumption), social inclusion (jobs and gender), equity (poverty and inequality), environmental quality (pollution and deforestation), and economic resilience (unexpected losses due to large shocks, including, for example, commodity price shocks, economic and financial crises, or protracted trends such as climate change and disruptive technologies). ${ }^{3}$ Furthermore, we are

\footnotetext{
${ }^{1}$ Savings in transport costs also form the focus of the social savings approach to assessing transport infrastructure impacts. This approach was pioneered by Fogel (1964) in his assessment of the benefits of the construction of the U.S. railroad system in the nineteenth century.

${ }^{2}$ It is sometimes argued that, even when the assumptions that underpin traditional CBA break down, it remains useful in providing a lower-bound estimate of the net benefits of a transport infrastructure project. However, this implicitly assumes that all the wider impacts not captured by a traditional CBA are, on net, positive. This may or may not be true.

${ }^{3} \mathrm{An}$ attempt was made to consider economic resilience as a development outcome. However, empirical literature that rigorously examines the impacts of transport infrastructure on economic resilience was found to be virtually nonexistent. One exception is Revoltella et al. (2016), who provide evidencefrom periods of both large positive and large negative economic shocks-of the catalytic role played by transport infrastructure in linking local businesses with global growth opportunities. Note that economic resilience, as defined in this paper, is different from the resilience of the transport infrastructure itself to shocks. Literature on this topic exists (see, e.g., Rozenberg, Briceno-Garmendia, Lu, Bonzanigo, \& Moroz, 2017), but it is not a direct subject of interest for this review.
} 
interested in the potential trade-offs that may occur between these different types of outcomes-for example, boosting income at the expense of rising pollution or inequality-as well as the heterogeneous impacts of transport projects on a given outcome across different places and economic agents-such as economic impacts that differ across subnational regions, industries, and population segments. These heterogeneities are hidden by estimates of average impacts. In some cases, they may involve only relative winners and losers. For instance, when all subnational areas along the route of a transport project gain, some may gain more than others. But, in other cases, the losses for some areas may be absolute.

To achieve greater rigor, this paper adopts a quantitative approach to reviewing the literature. We base our review on a meta-analysis of 97 papers that were published between 2000 and mid-2018. Taken together, these papers provide 337 individual results, which represent the sample for the quantitative analysis. This includes both simple descriptive analyses and formal econometric meta-regression analyses. The literature that we consider covers papers published in peer-reviewed academic journals and recognized working paper series, as well as gray literature that has not (yet) been published through a formal outlet and that is only available for download on authors' personal websites. ${ }^{4}$ In performing our review, we exclude literature that is solely concerned with the evaluation of purely urban transport infrastructure projects, ${ }^{5}$ as well as literature relating to the impacts of airline routes for which the potential for local economic spillovers is less clear. We also exclude literature in which more general transport-related variables appear in the empirical estimation, but these are either not related to evaluating the impacts of a particular transport infrastructure project and/or they appear as one of several general variables of interest. ${ }^{6}$

Notable recent reviews of literature on the impacts of large transport infrastructure projects include Redding and Turner (2014) and Berg et al. (2017). In both cases, the authors present qualitative reviews of the literature. In contrast, this paper provides a quantitative review of the literature, which includes the use of formal meta-regression analysis (MRA). We also consider a broader set of potential economic impacts than Redding and Turner (2014).

The remainder of the paper is structured as follows. Section 2 sets-out a simple framework that links transport corridor interventions with final development outcomes to help guide our analysis of the literature. Section 3 describes the criteria by which papers were selected for inclusion in the review. It also describes the tagging system that was developed to systematically capture the attributes of different papers and their associated results. Section 4 reports results from our descriptive analysis of the literature. Section 5 describes the MRA undertaken and discusses its main results. Section 6 concludes.

\section{I FRAMEWORK}

To provide a conceptual structure for the review, we use the simple framework outlined in Figure $1 .^{7}$ In this framework, the policymaker selects different features of a "transport corridor package" which include the transport mode(s) on which the corridor focuses (rail, road and/or waterways), the types of connections that the corridor is

\footnotetext{
${ }^{4}$ The inclusion of such literature is important to both assessing and, at least partially, addressing possible issues of publication bias, whereby the probability of publication in a formal outlet (especially in a peer-reviewed journal) is increased by the level of reported statistical significance of a result (see, e.g., Card, Kluve, \& Weber, 2010). Even if publication bias can be perfectly addressed, a serious potential issue of "writing-up bias" remains that cannot be addressed. This bias arises from the fact that authors may refrain from writing up results that are economically marginal or statistically insignificant, even in an initial, unpublished, draft version of a paper. Future research can address this bias through prepublication of econometric specifications to be estimated.

${ }^{5}$ See Redding and Turner (2014) for a discussion of the literature on the impacts of intraurban infrastructure.

${ }^{6}$ This includes a large empirical New Economic Geography (NEG) literature on the relationship between market access and either wage or gross domestic product per capita outcomes. For a meta-analysis of this literature, see Bosker and Garretsen (2010). It further includes a large empirical literature in macroeconomics, building on the work of Aschauer (1989), that analyzes the relationship between a country's stock of infrastructure, including its stock of transport infrastructure, and its level of development (for a review of this literature, see Straub, 2011).

${ }^{7}$ For a more detailed description of this framework see Section 2 of the earlier working paper version of this article (Roberts, Melecky, Bougna, \& Xu, 2017).
} 


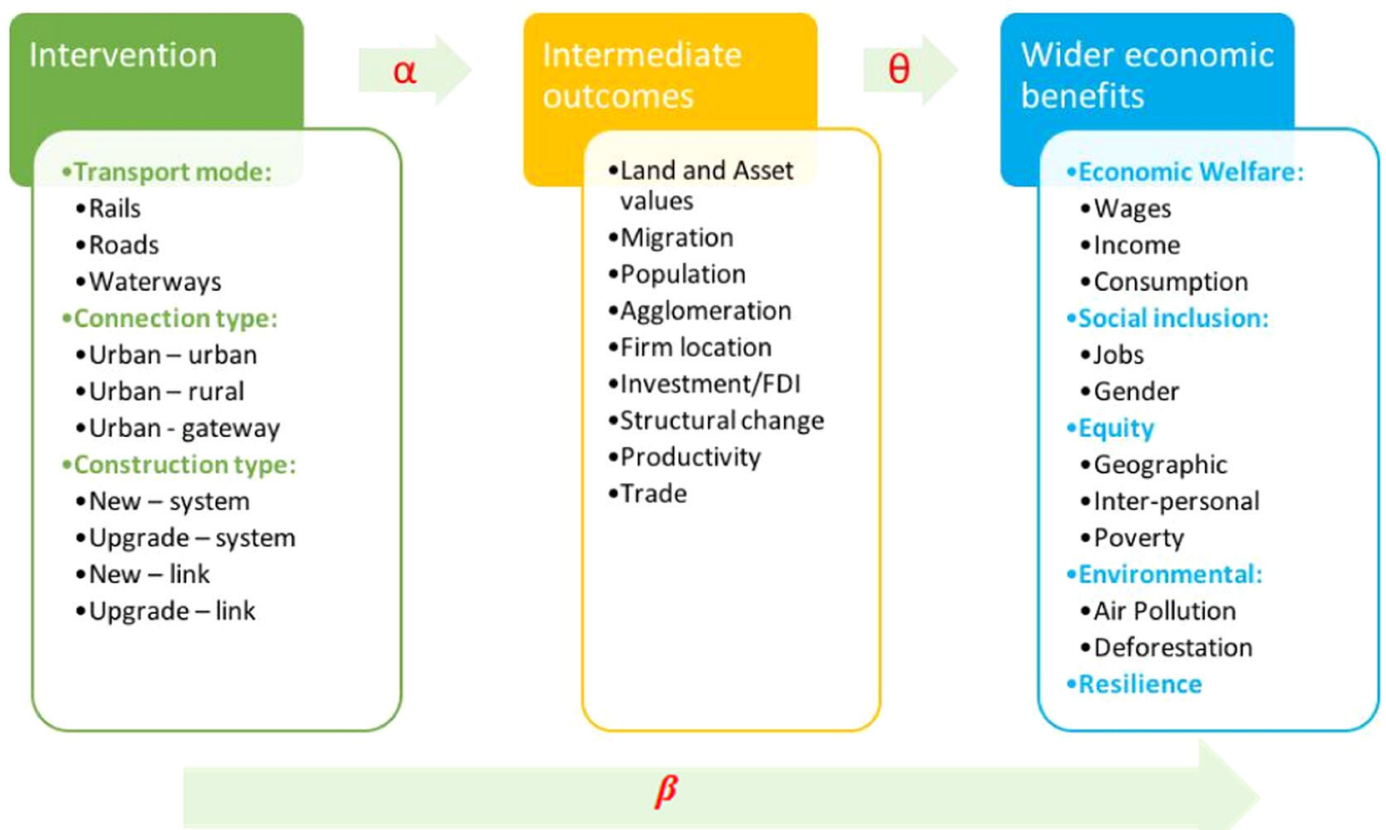

FIGURE 1 The chain of expected results. FDI, foreign direct investment [Color figure can be viewed at wileyonlinelibrary.com]

focused on promoting (i.e., urban-urban connections between major cities, urban-rural connections, and urbangateway connections between major cities and international gateways such as an international port, airport or a land-border crossing point), and the type of construction involved in the corridor (i.e., construction of an entirely new transport system, the upgrade of a pre-existing system, the construction of a new link within a pre-existing system, or the upgrade of a pre-existing link within a pre-existing system). Through a chain of expected results, the corridor package influences final development outcomes (i.e., WEBs net of costs)-where we categorize these outcomes as covering economic welfare, social inclusion, equity, environmental quality, and economic resilience-via a series of intermediate outcomes. The intermediate outcomes may include land and asset values, levels and patterns of migration, population levels, patterns of worker and firm agglomeration, levels of investment (including levels of foreign direct investment), the structural composition of economic activity, and levels of productivity and trade. ${ }^{8}$ In this results chain, $\beta$ describes the reduced-form effect of the corridor package on the final outcomes which itself is a function of $\alpha$ and $\theta$ (i.e., $\beta=\beta(\alpha, \theta)$ ), where $\alpha$ captures the strength of the relationship between the transport intervention and a given intermediate outcome, and $\theta$ the strength of the relationship between the intermediate outcome and the final outcome.

In this framework, $\alpha$ and $\theta$ depend on structural factors in land, labor and capital markets, as well as in product markets. For example, the extent to which migration responds to the corridor package depends on the extent of barriers to geographic labor mobility, while the responsiveness of investment may depend on barriers to market entry by firms. These structural factors may potentially be influenced by complementary interventions, which may include specific market policies and cross-cutting institutional reforms. Such complementary interventions may themselves form part of the corridor package alongside the selected features of the trunk transport infrastructure.

\footnotetext{
${ }^{8}$ Figure 1 depicts a simple linear flow from transport infrastructure investment to final outcomes via intermediate outcomes. However, in some senses, some of the intermediate outcomes may also be considered final outcomes. This is particularly the case with respect to the intermediate outcome variables of population, productivity, and land value.
} 


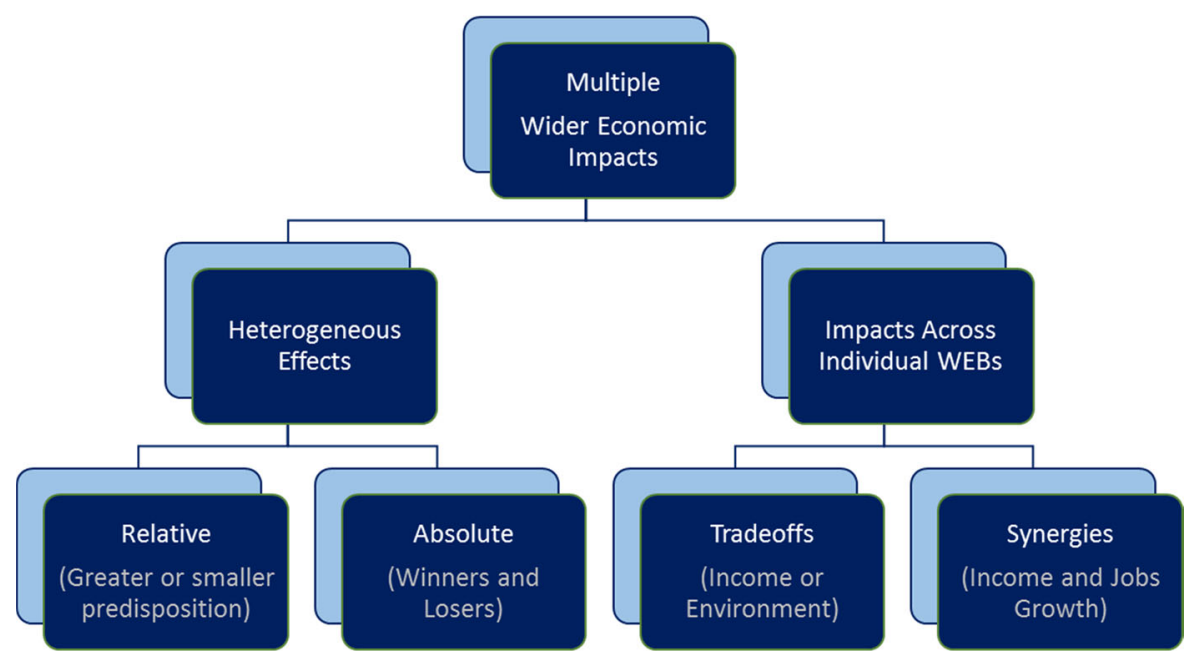

FIGURE 2 The hierarchy of multiple impacts [Color figure can be viewed at wileyonlinelibrary.com]

Ideally, we would like to know the socially optimal corridor package-defined as the package that maximizes the WEBs net of costs-under different sets of initial structural conditions in factor and product markets, as well as given the pre-existing state of transport infrastructure. However, less ambitiously, but more realistically, we focus on what the literature might (indirectly) reveal about how different corridor packages affect the net WEBs considering the expected results chain. For instance, how changing the types of nodes linked by a corridor or changing the mode of transportation on which the corridor focuses can affect development outcomes via the chain.

Hidden below the simple framework of Figure 1 is a variety of potential trade-offs and synergies both between different types of final development outcome (i.e., between WEBs) and between different localities or groups of economic agents for a given type of outcome. These impacts can be organized into a hierarchy (Figure 2). In this hierarchy, a transport corridor has potential impacts across multiple final outcomes (economic welfare, social inclusion, equity, environmental quality, and economic resilience). In some cases, these impacts may be positively correlated-for example, the corridor boosts both incomes and job creation-thereby leading to synergies, producing beneficial effects for both economic welfare and social inclusion. However, in other cases, the impacts may be negatively correlated-for instance, when economic welfare impacts are beneficial while environmental impacts are detrimental -thus leading to trade-offs between different outcomes. In addition to synergies and trade-offs between outcomes, impacts may be heterogeneous. Hence, for a given outcome, the impacts across different geographic areas, population segments, economic sectors, and the like could vary significantly. These heterogeneous impacts may be beneficial for everyone but of varying size (i.e., the effects are relative because of the greater or smaller predisposition of different population segments and locales to benefit). Or alongside winners, the transport infrastructure may create losers in absolute terms. For instance, people may lose jobs, towns may shed population and decay, and certain communities with bleak prospects and poor endowments may get left behind.

\section{3 | METHODOLOGY}

\subsection{Selection of papers}

Papers were identified for inclusion in this literature review through a three-step process. In step one, a long-list of papers for potential inclusion was identified by performing a series of Google Scholar searches based on different permutations of three categories of keywords: 
TABLE 1 Keywords used in Google Scholar searches

\begin{tabular}{|c|c|c|c|}
\hline \multirow[b]{2}{*}{ Transport related } & \multicolumn{2}{|l|}{ Outcomes } & \multirow[b]{2}{*}{ Additional } \\
\hline & Final & Intermediate & \\
\hline Road(s) & Income & Trade & Evaluation \\
\hline Expressway(s) & GDP & Firm location & Impact evaluation \\
\hline Highway(s) & Income per capita & Investment & Empirical \\
\hline Rail & GDP per capita & FDI & Econometric \\
\hline Railway(s) & Consumption & Productivity & Econometric analysis \\
\hline Railroad(s) & Growth & Population & \\
\hline Waterway(s) & Employment & Land value & \\
\hline Transport & Jobs & Agglomeration & \\
\hline Corridor(s) & Gender & Urbanization & \\
\hline Transport corridor(s) & Inequality & Structural change & \\
\hline \multirow[t]{3}{*}{ Economic corridor(s) } & Pollution & & \\
\hline & Deforestation & & \\
\hline & Resilience & & \\
\hline
\end{tabular}

Abbreviation: FDI, foreign direct investment; GDP, gross domestic product.

(a) Transport-related keywords

(b) Keywords relating to outcome variables of interest, including wider economic impact(s) and intermediate outcome(s)

(c) Additional keywords designed to capture the focus on empirical or econometric evaluation studies (see Table 1).

These searches were confined to papers published from 2000, which is around the time when rigorous empirical work on the impacts of large-scale transport infrastructure projects started to emerge in earnest, to mid-2018. Consistent with our framework in Section 2 (see Figure 1), a distinction was made between final outcomes (WEBs) and intermediate outcomes.

In step two, the papers identified in step one were subjected to two further screening criteria designed to narrow down the list. First, the paper must consider a "large" transport infrastructure investment, where "large" is defined as an investment that results in either:

(a) A significant improvement in connectivity between at least two major nodes of economic activity; or

(b) Extensive improvements in last-mile connectivity.

With respect to (a), the nodes of economic activity include either cities or international gateways. The condition that the investment improves connectivity between at least two major nodes was designed to reflect our underlying interest in transport corridors. ${ }^{9}$ Meanwhile, with respect to (b), extensive improvements in last-mile connectivity reflect, for example, widespread improvements in a rural road network that connects directly to a national network of highways and primary roads.

The second screening criterion required the paper to meet an "academic standard": namely, that the paper must present the results from original applied research involving statistical or econometric methods. In applying this standard, we were indifferent as to whether a paper was published through a formal academic outlet-such as in a peer-reviewed

\footnotetext{
${ }^{9}$ This does not rule-out the infrastructure from having potentially major impacts on more rural locations along the corridor. Indeed, the study of such impacts has been a major focus of the literature (see, e.g., Michaels, 2008)
} 
academic journal, a recognized working paper series such as the National Bureau of Economic Research (NBER) and Centre for Economic Policy Research working paper series or the World Bank Policy Research working paper series, or in an edited book volume-or just on an author's personal website. This allows us to capture so-called "gray literature" (literature not published in a peer-reviewed journal). In formal MRA, the inclusion of such literature is considered important to detect and mitigate publication bias (see, e.g., Card et al., 2010). ${ }^{10}$

In step three of the literature selection process, an attempt was made to capture any relevant papers that might have been missed from the list produced by steps one and two. This was done by analyzing the references in the papers from the list, consulting with World Bank experts in areas where we had found little coverage (such as about the impacts on economic resilience), and by visiting the personal websites of authors of papers in the list to identify additional "works in progress."

Following additional cleaning to weed out any obviously irrelevant or only marginally relevant literature, the application of the three steps resulted in a final sample of 97 papers. Figure 3 shows the break-down of papers by mode of publication. Of the 97 papers, $42 \%$ are non-journal papers which are less likely to be subject to publication bias, although only $2 \%$ are unpublished. From these 97 papers, a total of 337 separate estimation results were extracted. ${ }^{11}$

\subsection{Tagging of papers}

Having arrived at the list of papers for the review, a tagging system was applied to extract relevant information. An example of the application of this system is provided in Table 2. Information was collected from each paper for five basic categories of variables: publication details, intervention details, methodology, results, and additional. To ensure consistency in information collection across papers, the value for each variable was restricted to several multiple-choice options. ${ }^{1213}$

To maximize data collection accuracy, the tagging system was implemented using a double-blind review approach. Papers were reviewed and tagged independently by two trained research assistants (RAs) in batches of ten. Following the independent tagging of each batch of papers, a meeting would be convened to compare the results between the two RAs and reconcile differences. The meetings would also involve occasional over-riding of the tags chosen by both RAs based on the reading of the papers by the authors of this paper. ${ }^{14}$ As the papers were tagged, the tagging system was also refined to reflect our evolving understanding of the literature. ${ }^{15}$

\section{4 | DESCRIPTIVE STATISTICS}

This section provides a descriptive analysis of the data gathered from the sampled papers. It starts by briefly documenting the overall publication time-trend, taking this as representative of the overall trend in the level of academic interest in evaluating the impacts of major transport infrastructure projects. It follows by characterizing the "typical" (modal) paper in terms of such key details as the type of transport intervention that the paper focuses

\footnotetext{
${ }^{10}$ Although, as noted earlier, this does not prevent "writing-up bias", whereby less positive and statistically insignificant results are more likely to be discarded before any writing-up.

${ }^{11}$ This is less than the total number of results reported in the 97 papers. Typically, any given paper will report numerous regression results. We only extract results from the most relevant regressions, which typically constitute the authors' self-identified preferred specification(s).

${ }^{12}$ Appendix A provides a detailed list of these options, as well as descriptions of the variables.

${ }^{13}$ The tagging of papers is accurate for the date on which they were tagged. In a few cases, a paper that may have been, for example, a working paper at the time of tagging may subsequently have been published in a journal.

${ }^{14}$ Before the tagging system was formally applied, an initial dummy run was undertaken using a sample of 10 papers. This dummy run was used both to help train the RAs in the system and identify any initial obvious areas for improvement in the system. The results from this dummy run were discarded and the papers subsequently reviewed again.

${ }^{15}$ Table 2 and Appendix A present the final tagging system. Seventy-eight papers were tagged between September 2016 and March 2017 . In response to referee comments, a further 19 papers were tagged between September and December 2018.
} 


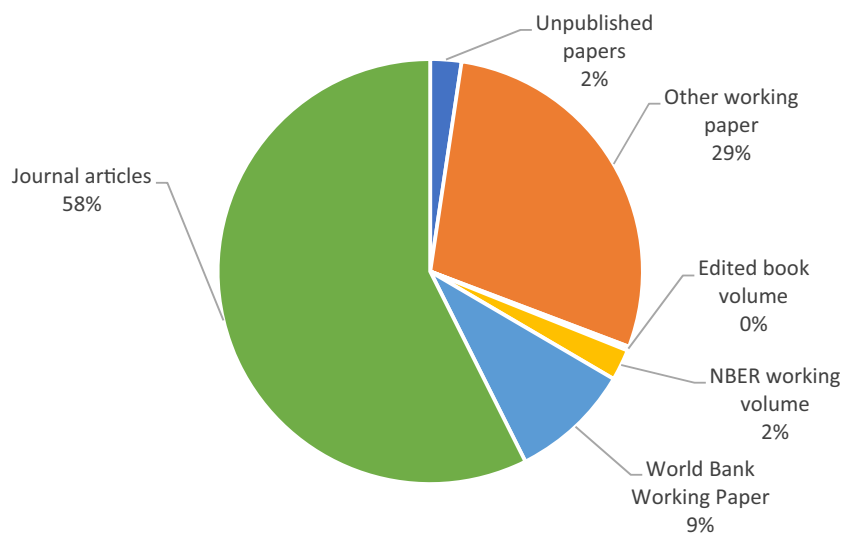

FIGURE 3 Mode of publication of sample papers. Ninety-seven papers with 337 results (analyzed outcomes) tagged by December 2018 [Color figure can be viewed at wileyonlinelibrary.com]

on, the methodology employed, and the outcome variables that the paper examines. It then proceeds to a descriptive analysis of the literature in terms of the results reported across both the different categories of final and intermediate outcomes identified in Figure 1.

The discussion first considers average impacts before moving on to considering heterogeneous impacts, where heterogeneous impacts can occur along different dimensions (such as heterogeneous impacts across geographic areas vs. heterogeneous impacts across different industries or population segments). Such heterogeneous impacts imply the existence of relative "winners" and "losers." However, in some cases, losers may experience absolute losses. Thus, we describe the evidence from the literature on the existence of absolute losses as part of the discussion of heterogeneous impacts. Finally, we describe the extent to which the literature, in its estimation of impacts, considers the effects of complementary interventions-defined as policies or institutional reforms that are designed to amplify the net WEBs associated with the construction of a transport corridor. This amplification may occur either through the enhancement of the beneficial impacts of a transport corridor on a given outcome or the mitigation of trade-offs between different outcomes.

\section{1 | Publication time-trend, typical paper, intervention, and methodology}

\subsection{1 | Publication time-trend}

Figure 4 shows the distribution of sampled papers by year of publication. For unpublished (i.e., "work in progress") manuscripts that appear only on an author's personal website, the year of publication corresponds to the date on the manuscript. The trend in terms of number of papers published per year has been strongly upward. While only five papers in the sample were published over the years 2000-2002, 38 were published over the years 2016-2018. This strong upward trend reflects the growing academic focus on rigorously evaluating the impacts of major transport infrastructure projects.

\subsubsection{Geographical focus of the typical paper}

For the purposes of this study, the typical paper is the modal paper. Table A1 in Appendix A tabulates the distribution of papers by country or-in the case where a paper relates to several countries-the region of study. Of the 97 papers in the sample, 40 papers-or $42 \%$ of the total-focus on transport infrastructure projects in just three countries: the United States (15 papers), India (11 papers), and China (14 papers). The strong focus on these three countries reflects the extremely large-scale transport infrastructure projects that these countries have undertaken either in recent decades or 


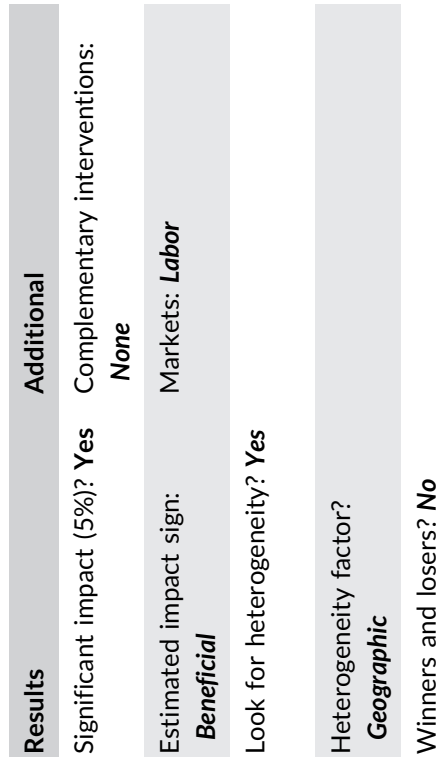

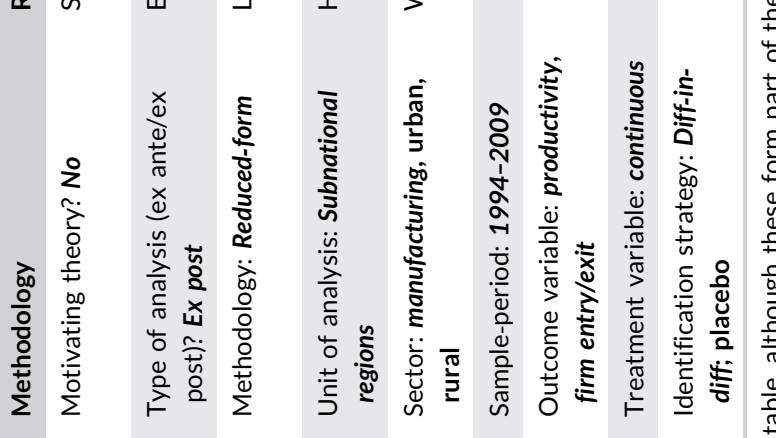

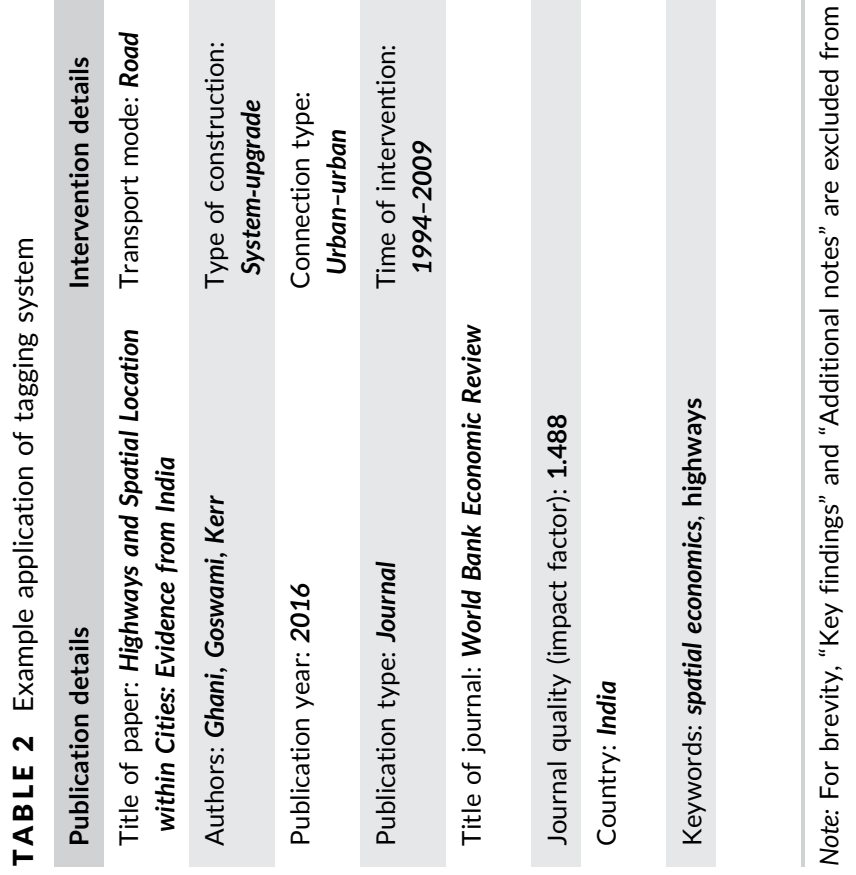




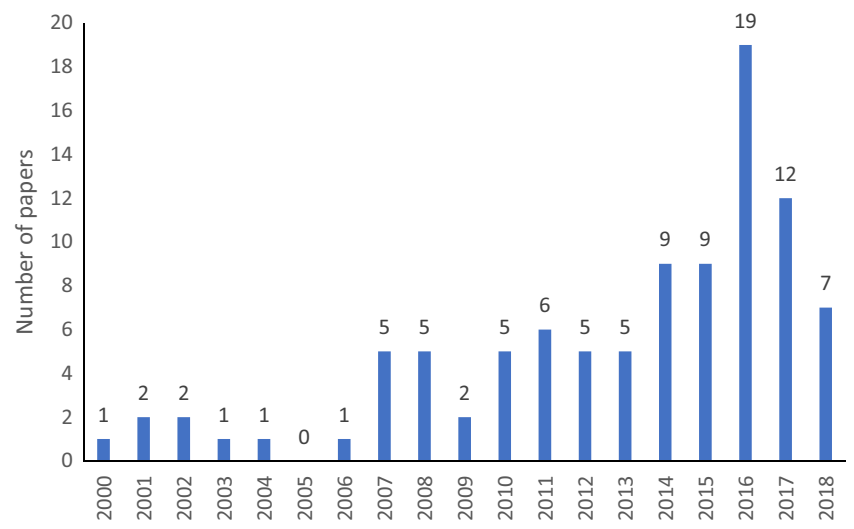

FIGURE 4 Number of papers by year of publication. Ninety-seven papers with 337 results (analyzed outcomes) tagged by December 2018 [Color figure can be viewed at wileyonlinelibrary.com]

historically. Over the last 25 years, both China and India have constructed major new highway networks-the National Expressway Network (NEN) in the case of China (constructed between 1992 and 2015) and the Golden Quadrilateral (GQ) network in the case of India (constructed between 2001 and 2012). Examples of papers that focus on the evaluation of China's NEN include Roberts, Deichmann and Shi (2012), Faber (2014), and Baum-Snow et al. (2018), while Alder (2015), Ghani et al. (2016, 2017) and Khanna (2016) are examples of papers that focus on India's GQ. ${ }^{16}$ Historically, extensive national railway networks were constructed in both the United States and India in the nineteenth and early twentieth centuries. The evaluation of these networks has been the subject of several papers (Atack \& Margo, 2011; Donaldson, 2018; Donaldson \& Hornbeck, 2016; Haines \& Margo, 2006; Herrendorf, Schmitz, \& Teixeira, 2012). Crucially, these evaluations have been facilitated by the existence of high-quality historical data on both the networks themselves and relevant outcome variables. In the second half of the twentieth century, the United States also constructed its Interstate Highway System, which has been the focus of many papers (e.g., Baum-Snow, 2007; Chandra \& Thompson, 2000; Michaels, 2008).

Beyond the United States, India, and China, significant numbers of papers focus on either African countries (16 papers) or Latin American countries (17 papers). Several of them focus on environmental outcomes, especially on the impacts of roads on deforestation (see, among others, Conde, 2008; Damania \& Wheeler, 2015; Dasgupta \& Wheeler, 2016; Pfaff et al., 2007; Weinhold \& Reis, 2008). Unlike papers for other regions, several of the papers examining transport investments in Africa focus explicitly on transport networks that cut across national boundaries and therefore cover more than one country (see, e.g., Buys, Deichmann, \& Wheeler, 2006; Jedwab \& Storeygard, 2017).

\subsection{3 | Intervention details}

The typical paper focuses on road transport infrastructure. More than three-quarters (78\%) of 337 reported results evaluate the impacts of some sort of road transport infrastructure (Figure 5a). The only other transport mode that receives significant attention in the literature is rail (17\% of results). The overwhelming focus on road networks reflects, in part, the focus on evaluating the impacts of the NEN in China and the GQ in India, as well as the impacts of the Interstate Highway System in the United States. As mentioned, all these systems were newly constructed networks. Hence, unsurprisingly, 74\% of results in the sample focus on the evaluation of new network systems (Figure 5b). By contrast, 15\% examine the upgrading of a pre-existing transport system, while $5 \%$ of results evaluate the impacts of upgrading an individual link within a broader transportation network.

${ }^{16}$ China has also been engaged in the construction of an extensive high-speed railway network that has attracted some attention in the literature (see, e.g., Wang, 2013). 
(a) Transport mode

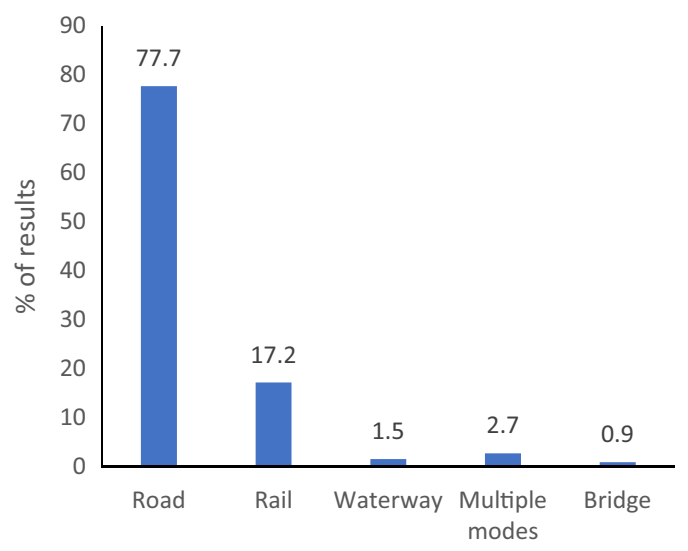

(b) Construction type

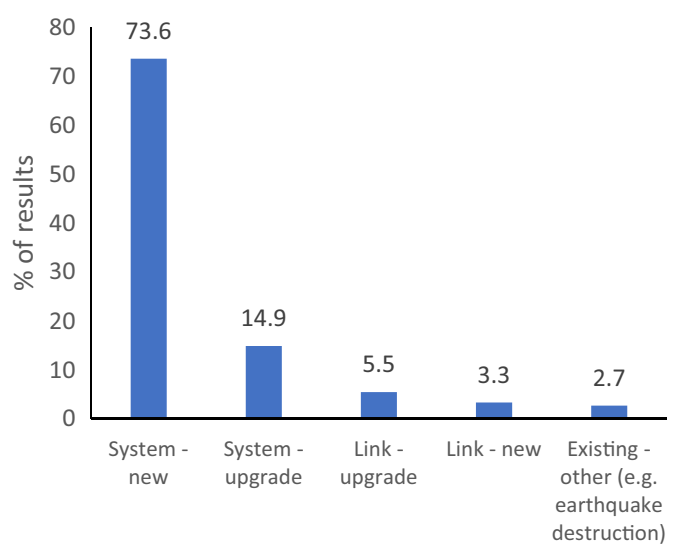

FIGURE 5 Distribution of results by transport mode and construction type. Ninety-seven papers with 337 results (analyzed outcomes) tagged by December 2018 [Color figure can be viewed at wileyonlinelibrary.com]

As for the type of connection considered, the typical paper focuses either on projects that are designed to link urban centers $(46 \%)$ or on the impacts of urban-rural connections (43\%). Typically, the focus is on evaluating connections between places that fall within national boundaries, except for several papers on Africa, including Buys et al. (2006) and Jedwab and Storeygard (2017). However, several studies (11\%) focus on evaluating the impacts of connections between one or more urban centers and an international gateway (a port, an airport or a land-border crossing point). Examples include Coşar and Demir (2016) and Volpe Martincus and Blyde (2013). The preoccupation of the literature with connections that fall wholly within national borders is, again, related to the dominance of China, India, and the United States as countries of study.

\subsection{4 | Methodology}

Papers most frequently focus on "economic welfare" as the category of final outcomes (Figure 6a) and "population and assets" and "trade and productivity" as intermediate outcomes (Figure 6b).

The typical paper uses subnational geographical regions-such as Indian tehsils (Alder, Roberts, \& Tewari, 2017; Khanna, 2016), Chinese counties (Banerjee, Duflo, \& Qian, 2012), and electoral wards in the United Kingdom (Gibbons, Lyytikäinen, Overman, \& Sanchis-Guarner, 2019)-as the unit of analysis (Figure 7a). ${ }^{17}$ About $84 \%$ of sampled papers rely on data for such regions, whereas $11 \%$ utilize micro-data for individual households. By contrast, a mere $2 \%$ of papers use micro-data for firms (examples include Gertler, Gonzalez-Navarro, Gracner, \& Rothenberg, 2014; Martincus, Carballo, \& Cusolito, 2016; and Volpe Martincus \& Blyde, 2013). Most papers (90\%) focus on ex post evaluation (Figure 7b).

The typical paper is also explicitly motivated by some underlying theoretical model-quite often an economic geography model of trade (Figure 8a)-and relies on reduced-form (RF) estimation (Figure 8b). ${ }^{18}$ Hence, $78 \%$ of results use RF estimation, while $16 \%$ evaluate the impacts of transport infrastructure using a structural model. RF estimation tends to rely on a difference-in-difference (DID) estimator in which the impacts of, for instance, treated

\footnotetext{
${ }^{17} \mathrm{~A}$ recent innovation in the literature has been to use subnational "grid cells" of uniform area as units of analysis (Ali et al. 2015; Jedwab \& Storeygard, 2017).

${ }^{18}$ Economic geography models of trade include both "new economic geography" models (Fujita, Krugman, \& Venables, 1999; Krugman, 1991a, 1991b) and Ricardian models of internal trade of the Eaton-Kortum (2002) variety. Examples of papers that are motivated by a NEG model include Roberts et al. (2012), while Costinot et al. (2011), Donaldson and Hornbeck (2016), Alder (2015), and Alder et al. (2017) are examples of papers motivated by an EatonKortum style Ricardian trade model.
} 
(a) Final outcomes $(\%)$

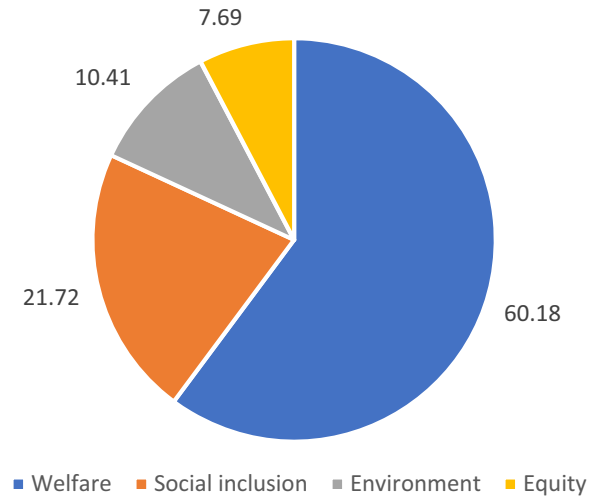

(b) Intermediate outcomes (\%)

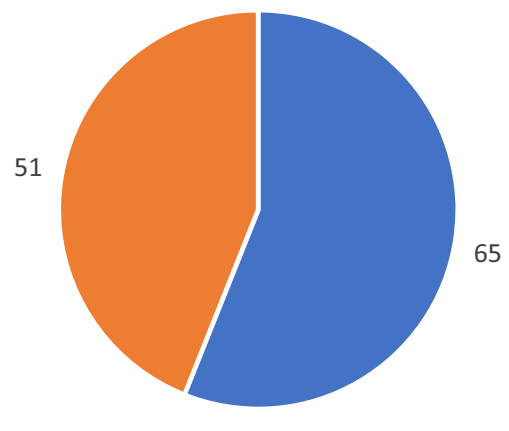

- Population \& assets = Trade \& productivity

FIGURE 6 Distribution of results by type of outcome. Ninety-seven papers with 337 results (analyzed outcomes) tagged by December 2018 [Color figure can be viewed at wileyonlinelibrary.com]

subnational regions are evaluated against those of a set of comparison regions before and after the occurrence of the infrastructure investment. Such estimation focuses on the identification of impacts in the immediate geographic vicinity of the investment without explicitly seeking to identify the mechanisms through which such impacts occur (see, e.g., Ghani et al., 2016, 2017). Meanwhile, papers that use a structural model, such as Alder (2015) and Asturias et al. (2018), focus on a specific mechanism, which is normally related to internal trade. Finally, $6 \%$ of sample results use a computable general equilibrium (CGE) model. These results are invariably from papers that

(a) Units of analysis (\%)

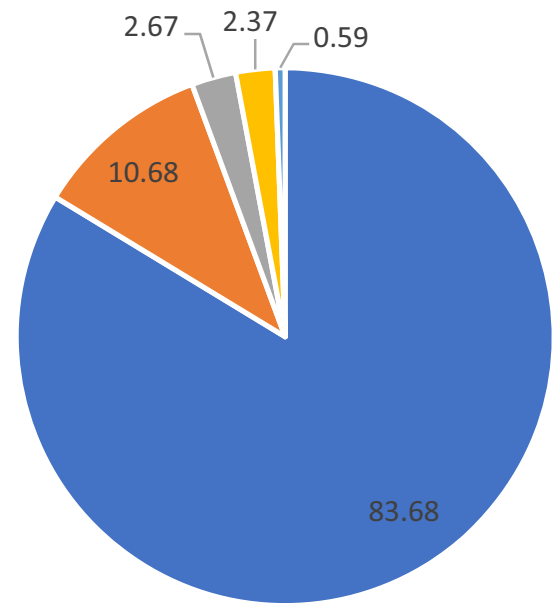

- Subnational regions - Households

= Countries $\quad$ - Firms

- Other (b) Type of analysis (\%)

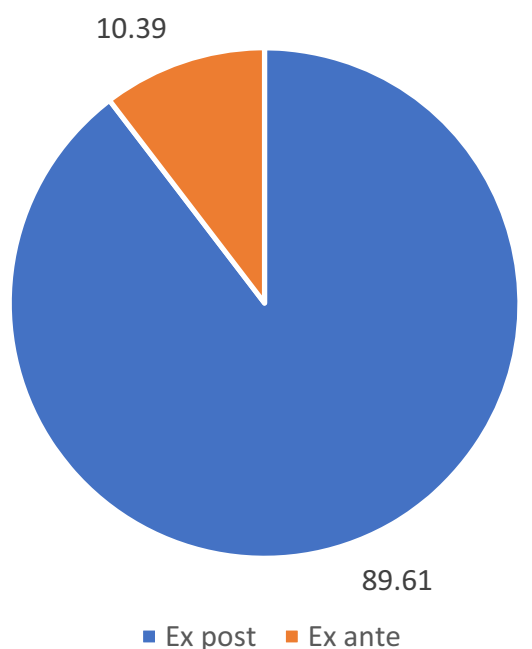

- Ex post - Ex ante

FIGURE 7 Distribution of results by unit of analysis and by type of analysis. Ninety-seven papers with 337 results (analyzed outcomes) tagged by December 2018 [Color figure can be viewed at wileyonlinelibrary.com] 
(a) Motivating theory? (\%)

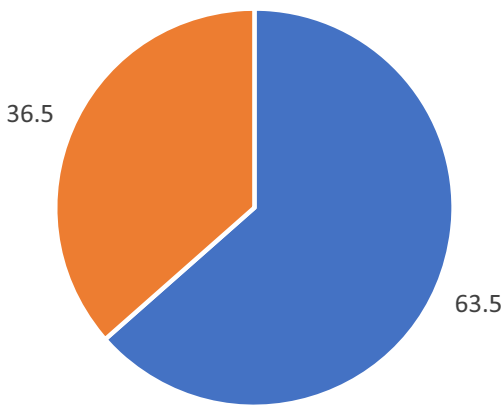

Yes $=$ No (b) Estimation methodology used (\%)

6

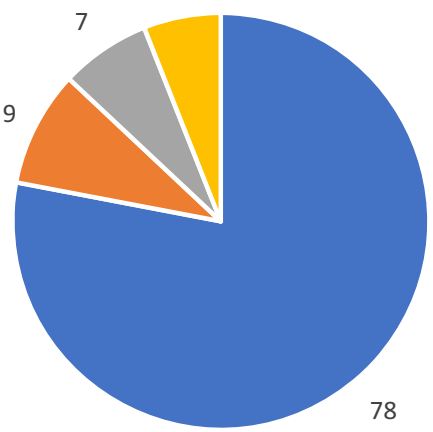

- Reduced form

- Structural model - estimation \& calibration

- Structural model - system estimation

ఐ Computable General Equilibrium

FIGURE 8 Share of results motivated by some underlying theoretical model, and the methodologies used. Ninety-seven papers with 337 results (analyzed outcomes) tagged by December 2018 [Color figure can be viewed at wileyonlinelibrary.com]

undertake ex ante impact evaluation analysis (such as Arman, Manesh, \& Izady, 2015). ${ }^{19}$ Structural and CGE-based approaches to evaluation possess the advantage over RF regressions that, in principle, they can separate out the creation of new activity from the redistribution of existing activity. However, the downside of these approaches is that they make the strong assumption that the true underlying structure of the economy is known. ${ }^{20}$

Finally, the typical paper pays strong attention to trying to address the issue of biased estimation of impacts arising from the endogenous placement of transport infrastructure. Indeed, addressing this issue has become the literature's overwhelming empirical concern (Berg et al., 2017; Redding \& Turner, 2014). Endogenous placement concerns arise from the fact that the locations that policymakers chose to link with transport infrastructure are not random. In principle, this can lead ordinary least squares (OLS) estimation to either over- or under-estimate the impacts of the infrastructure. For example, if the outcome variable is a measure of local economic activity, over-estimation is more likely if policymakers deliberately target the linking of locations that they, in any case, expect to grow quickly. By contrast, under-estimation is more likely if policymakers deliberately prioritize connections to lagging regions with low underlying economic potential. $64 \%$ of sample results adopt an explicit identification strategy to address endogeneity concerns (Figure 9a). Such identification strategies most frequently involve an instrumental variable (IV) approach, ${ }^{21}$ although additional strategiessuch as the use of a placebo strategy in Donaldson (2018)-have also emerged in recent years (Figure 9b). A recent trend in the "strongest" papers has been to employ multiple strategies-for example, both IV and placebo strategies-to convince the reader that estimated impacts are accurately identified (see Ghani et al., 2016). The papers that focus on the economic welfare category of final outcomes are the most advanced in their attention to endogeneity concerns. By contrast, papers

\footnotetext{
${ }^{19}$ The literature would benefit from more work comparing the results of ex ante and ex post evaluations of major transport infrastructure projects along the lines of that conducted by Kiel et al. (2014), who compare ex ante and ex post results for five different projects, including the Amsterdam orbital highway, the Lyon-Budapest rail corridor, and the Barcelona-Madrid high-speed rail corridor

${ }^{20}$ Baum-Snow et al. (2016) provide a comparison of results for the impacts of the construction of China's NEN obtained using RF estimation and a structural-specifically, Eaton-Kortum-model. They demonstrate that "technique matters"-that is, the results obtained depend fundamentally on the approach adopted. They also provide evidence to show that the Eaton-Kortum model misses some quantitatively important features that are evident in the data.

${ }^{21}$ Redding and Turner (2014) identify three main types of IV-strategy that are employed in the literature: the "planned route IV," the "historical route IV," and the "inconsequential units approach."
} 
(a) Identification strategy? (\%)

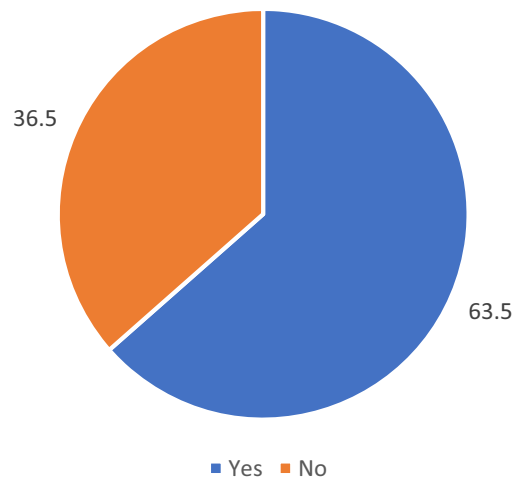

(b) Identification strategies employed (\%)

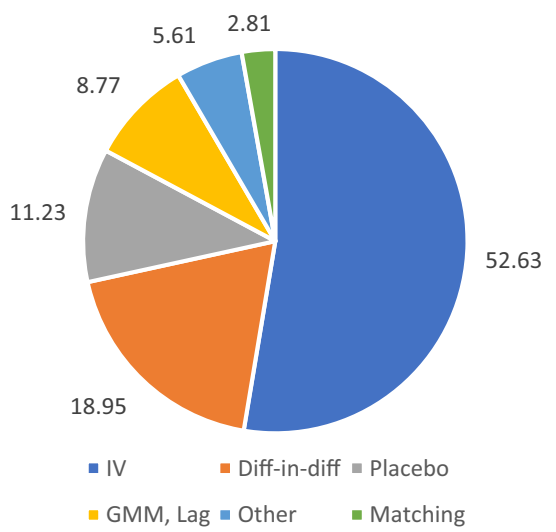

FIGURE 9 Share of results that employ an identification strategy to address endogeneity concerns and identification strategies employed. Ninety-seven papers with 337 results (analyzed outcomes) tagged by December 2018. GMM, generalized method of moments; IV, instrumental variable [Color figure can be viewed at wileyonlinelibrary.com]

that focus on other outcomes, such as environmental outcomes, tend to pay relatively little attention to endogenous placement concerns.

\section{2 | Descriptive analysis of results}

\subsection{1 | Estimated average impacts}

The 97 papers in the sample cover 337 separate results. Our analysis of these results reveals that the literature provides evidence of statistically significant WEB impacts (at the $5 \%$ level or greater) on economic welfare, social inclusion, equity, and environmental quality (Figure 10a). For a given type of outcome, the amount of confidence that can be attached to this evidence depends on both the number of results reported and the proportion of those results that are significant. In this sense, the evidence of significant impacts on economic welfare outcomes is relatively strong. One hundred and thirty three results relate to this type of outcome, of which 112 , or $84.2 \%$, are statistically significant. For social inclusion, equity, and environmental quality outcomes, the proportion of reported impacts that are statistically significant are similarly high. However, in each case, the number of results is far fewer (41 for social inclusion, 16 for equity, and 23 for environmental quality). The sample contains no results for the WEB of economic resilience, which highlights a prominent blind-spot in the literature. As for intermediate outcomes, considerable evidence exists that transport infrastructure has significant impacts on both population and assets (such as land values), as well as on levels of trade and productivity (Figure 10b). For population and assets, 56 out of 65 reported impacts are statistically significant, while for trade and productivity, 48 out of 51 are significant.

The estimated average impacts on the various types of WEBs are mainly beneficial. ${ }^{22}$ Hence, most reported impacts on levels of real income, poverty, and consumption are beneficial. However, there are some notable exceptions. Thus, all reported results for environmental quality outcomes are detrimental. Likewise, the analysis reveals evidence of transport infrastructure projects having significant detrimental effects on jobs in more than $20 \%$ of cases (Figure 11). This implies that major transport infrastructure projects can entail trade-offs between different types of outcomes. While average impacts on economic welfare tend to be positive, this can come at the potential cost of worse outcomes for social inclusion and especially environmental quality. The existence of such trade-offs suggests an important potential role for complementary interventions.

\footnotetext{
${ }^{22}$ We use the words "beneficial" and "detrimental" to refer to impacts that we respectively expect to enhance or diminish social welfare. For example,
} increases in levels of real income and jobs are beneficial, while increases in rates of poverty and inequality are detrimental. 
(a) Wider economic benefits

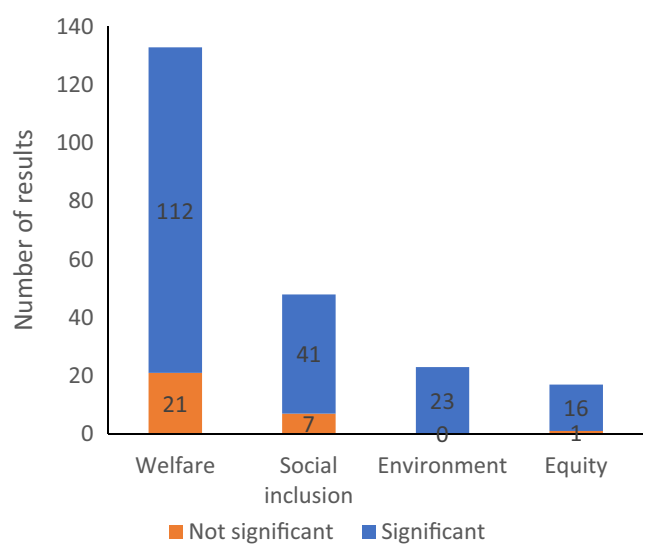

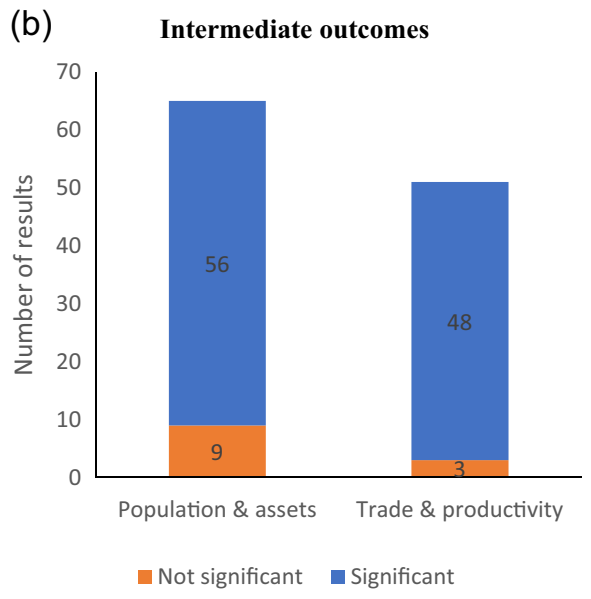

FIGURE 10 Distribution of results in terms of statistical significance at the $5 \%$ level. Ninety-seven papers with 337 results (analyzed outcomes) tagged by December 2018 [Color figure can be viewed at wileyonlinelibrary.com]

Similarly, for intermediate outcomes, while average impacts are mainly found to be beneficial, detrimental results are sometimes reported for some variables. More specifically, the evidence suggests that investment in transport infrastructure tends to reduce prices and boost levels of investment, trade, and productivity, while also promoting industrial diversification and allocative efficiency. However, in some cases, detrimental impacts on levels of trade, population, and land values are reported (Figure 12). Some care is required in interpreting what constitutes a detrimental impact in terms of population and land values from both a welfare and productivity perspective. For example, Baum-Snow (2007) provides evidence to show that the construction of new limited access highways in the United States between 1950 and 1990 contributed to suburbanization by inducing population de-concentration away from central city areas. However, while we tag this as a "detrimental" impact in terms of a central city's population, it is not clear that it is detrimental from an overall social welfare perspective.

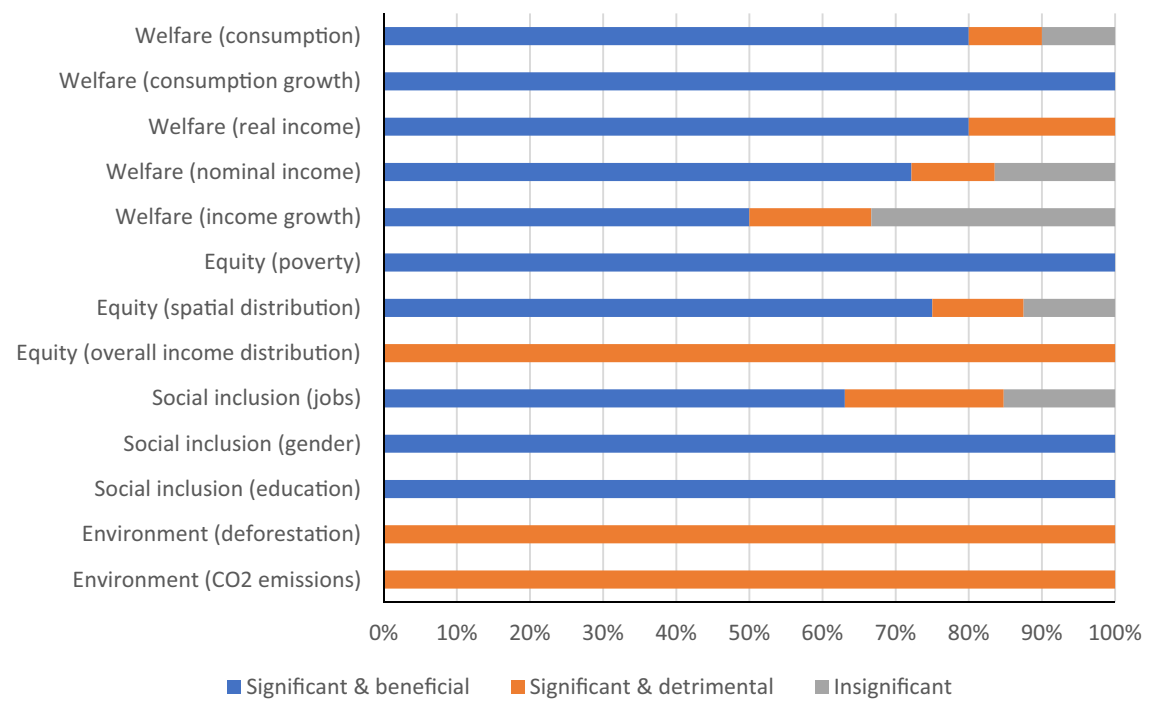

FIGURE 11 Distribution of significant results for WEBs according to whether they are beneficial or detrimental. Significance is measured at the $5 \%$ level. Ninety-seven papers with 337 results (analyzed outcomes) tagged by December 2018 [Color figure can be viewed at wileyonlinelibrary.com] 


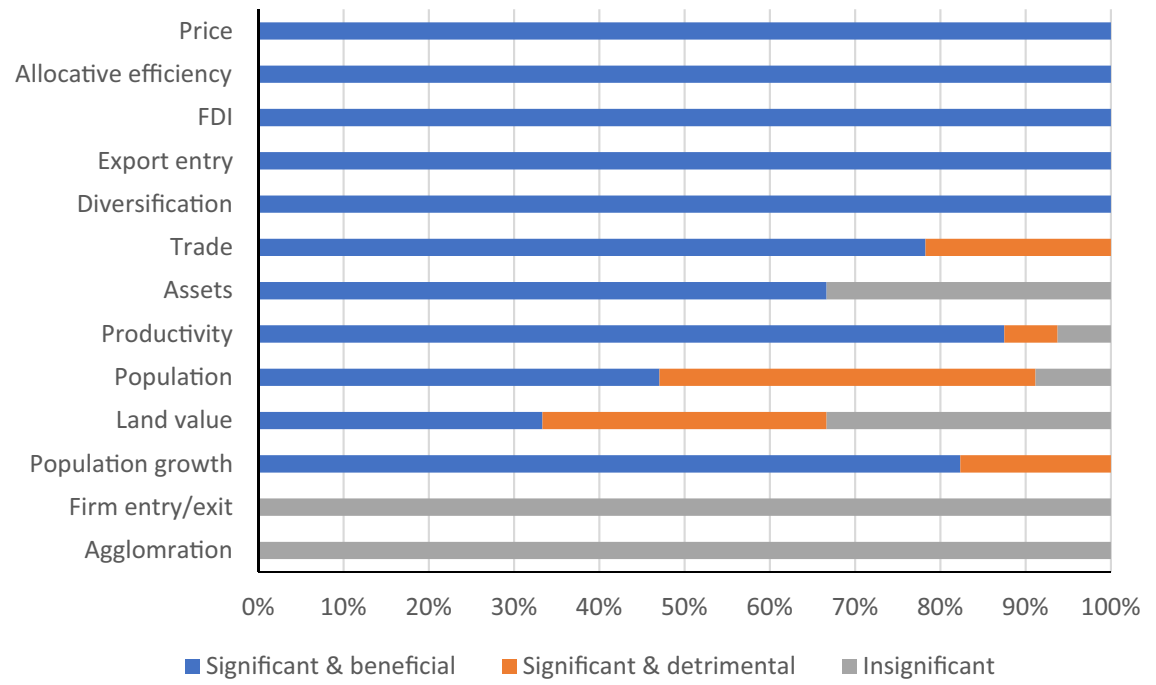

FIGURE 12 Distribution of results for intermediate outcomes according to whether they are significantly beneficial or detrimental. Significance is measured at the $5 \%$ level. Ninety-seven papers with 337 results (analyzed outcomes) tagged by December 2018 [Color figure can be viewed at wileyonlinelibrary.com]

\subsection{2 | Evidence of heterogeneous impacts}

As shown by Figure 13, there has been a growing trend in the literature to move beyond estimating average impacts of transport infrastructure to analyzing how these impacts vary across the different units of analysis considered in a study. Given that most papers use subnational regions as their unit of analysis, it is no surprise that the dimension along which heterogeneity is most commonly analyzed is geographic (Figure 14). ${ }^{23}$ The analysis of how impacts vary across sectors and over time also receives some attention, ${ }^{24}$ but the literature provides very little evidence on whether, and how, impacts may vary across, for example, differently endowed individuals.

Evidence of heterogeneous impacts implies that, for example, some geographic areas or groups of households or firms gain more relative to others from transport infrastructure improvements. In some cases, however, the losses may not only be relative, but also absolute. Indeed, among the subsample of results that look for evidence of possible heterogeneous impacts, many do find evidence of absolute losses, even for outcomes where overall average impacts tend to be overwhelmingly positive. Roberts et al. (2012) provide one such evidence in their results. They report that the construction of the NEN increased real income across Chinese prefectures by, on average, just $<4 \%$. However, in a fair number of prefectures, the construction had a negative impact on real wages in either the urban or rural sector. Hence, in terms of WEBs, evidence of absolute losers alongside absolute winners is reported for both economic welfare and social inclusion outcomes. Relatedly, evidence of absolute losers alongside winners exists for the intermediate outcomes of population, trade, and land values (Figure 15). ${ }^{25}$ The conclusion to be drawn is that major transport infrastructure projects can entail policy trade-offs not only between different types of WEBs (e.g., economic welfare vs. environmental quality), but also between different geographic areas and subgroups for a given outcome.

\footnotetext{
${ }^{23}$ Any given result may analyse heterogeneity across one or more dimensions.

${ }^{24} \mathrm{~A}$ particularly interesting paper in this regard is Pereira et al. (2014). It analyzes the overall impact of railroad investment on economic growth in the Antebellum United States. In doing so, it adopts a bivariate dynamic time series methodological approach, based on the use of a vector autoregressive model, which is very different from the more cross-sectional approaches adopted by most of the literature. The use of this approach allows the authors to distinguish short-run demand-side effects associated with railroad construction on economic growth from longer-run supply-side effects.

${ }^{25} \mathrm{Again}$, some care in interpretation is required here. Although a subnational region may experience a decline in population due to a transport project that better connects it to other regions, it is not necessarily clear that this makes the region a "loser" from a welfare and productivity perspective. A loss in population may, for example, stimulate an overall increase in productivity and real wages for the region if it helps to ease congestion within the region.
} 


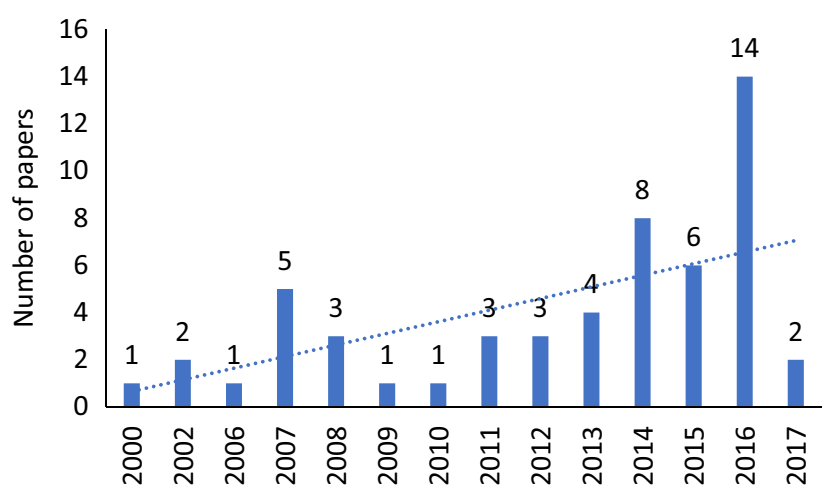

FIGURE 13 The growing trend to analyze heterogeneous impacts. Ninety-seven papers with 337 results (analyzed outcomes) tagged by December 2018 [Color figure can be viewed at wileyonlinelibrary.com]

\subsection{3 | Complementary interventions}

Evidence of trade-offs between both different types of WEBs and different subgroups for a given WEB suggests a potentially important role for complementary interventions designed to mitigate these trade-offs. Unfortunately, out of the 337 results analyzed, only $14 \%$ investigate how complementary interventions may influence a transport infrastructure project's impact on a given outcome. The lacking analysis of the role that complementary interventions may play, in part, reflects the literature's preoccupation with isolating the effects of a transport infrastructure project from other, potentially confounding, influences for the purposes of clean identification. When papers do explicitly analyze the role of potentially complementary interventions, they tend to focus on labor market policies and adopt a more structural modelling approach. ${ }^{26}$ Papers that focus on environmental quality outcomes, especially deforestation, also provide an important exception, as these frequently also consider the role of protected area status in mitigating the impacts of roads on deforestation (Cropper, Puri, \& Griffiths, 2001; Damania \& Wheeler, 2015; Dasgupta \& Wheeler, 2016).

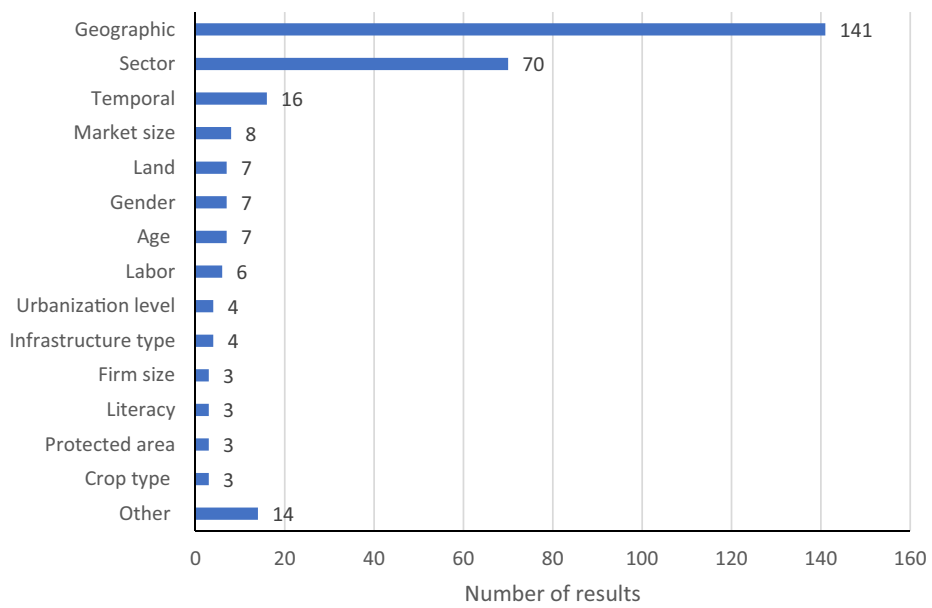

FIGURE 14 Number of results by heterogeneity factor. Ninety-seven papers with 337 results (analyzed outcomes) tagged by December 2018 [Color figure can be viewed at wileyonlinelibrary.com]

\footnotetext{
${ }^{26} \mathrm{~A}$ good example of this is the paper by Bosker et al. (2018), which analyzes both the national and spatial impacts of the NEN in China on levels of real income, while simultaneously considering how these impacts have been influenced by restrictions on migration associated with the country's permanent household registration (Hukou) system.
} 
(a)

Final outcomes

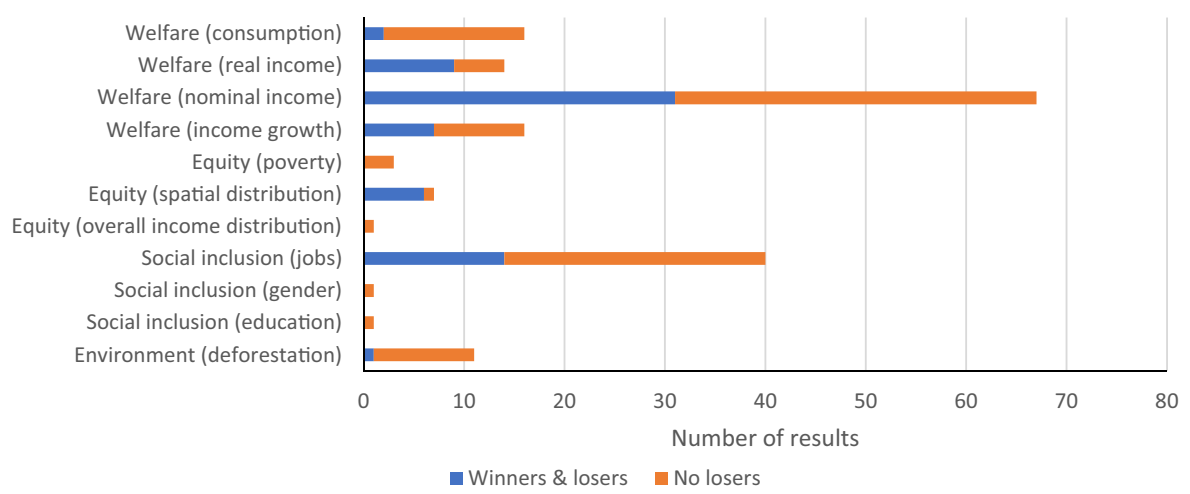

(b)

Intermediate outcomes

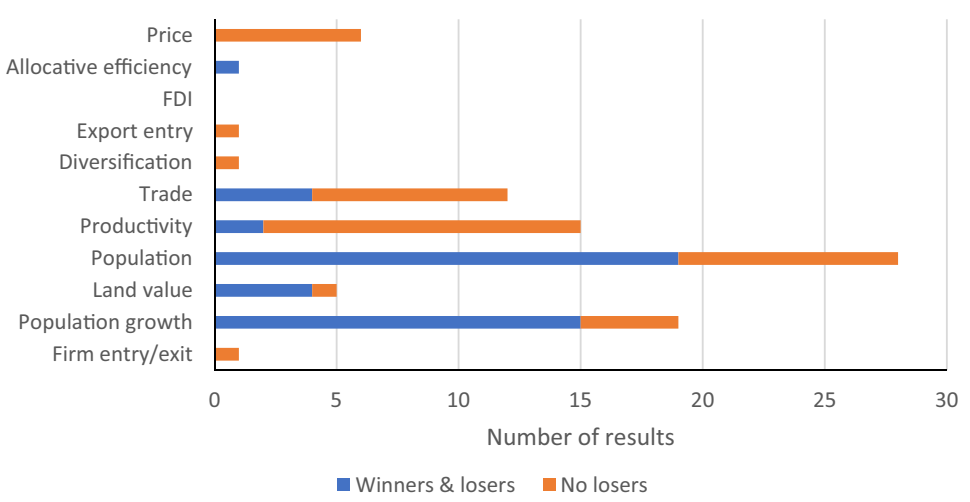

FIGURE 15 Distribution of results that analyze heterogeneity according to whether they report evidence of absolute losers. Ninety-seven papers with 337 results (analyzed outcomes) tagged by December 2018 [Color figure can be viewed at wileyonlinelibrary.com]

\section{5 | META-REGRESSION ANALYSIS}

This section presents the results of a formal MRA of the literature. MRA is a quantitative tool that helps synthesize findings from diverse empirical studies of a phenomenon. It has become a commonly used methodology in the social sciences. By combining the results from multiple papers into a single statistical analysis, it allows primary effects to be distinguished from background variation and contaminating influences (Stanley and Doucouliagos, 2010).

The MRA that we undertake is intended to shed light on two questions. First, can the variations in the estimated impacts of large-scale transport infrastructure projects reported in the literature be explained by variations in the characteristics of the projects themselves and by observed methodological variations across papers? Second, are there policy-relevant insights that emerge from the literature? For example, is there evidence that certain features of projects (such as the mode of transportation or the type of locations they connect) are, on average, associated with better (more beneficial) outcomes?

The major problem that we face in implementing our MRA is that the impacts of interest relate to a diverse set of outcomes and are derived using an equally diverse set of treatment variables for different countries based on a nonuniform set of modelling approaches. As such, estimated coefficients on the treatment variable are not comparable across different papers. In some cases, they are not even comparable across different regression results reported within a paper. To overcome this issue, as well as possible 
problems with heteroscedasticity, we divide (weight) the dependent variable by the estimated standard deviation of the treatment coefficient following, among others, Stanley and Jarrell (1989), Stanley and Doucouliagos (2010), Chen et al. (2012), De Groot et al. (2016), and Havránek et al. (2015). Specifically, we use the reported $t$ statistic for the coefficient on the treatment variable as our measure of impact rather than the actual treatment coefficient itself. This allows us to standardize results across different papers and model specifications. Importantly, a higher reported $t$ statistic can result from either a higher estimated treatment effect of the transport infrastructure or a more precisely estimated-that is, a more certain-treatment effect. We implement our MRA using the sample of results for final outcomes (WEBs) only, leaving MRA of results for intermediate outcomes for future research. In doing so, we also necessarily drop estimates of treatment effects based on CGE models from our sample because these estimates lack accompanying $t$ statistics.

\section{1 | The estimated multivariate model}

We use the OLS model as our baseline regression model and estimate Equation (1) below in which we relate the reported treatment effect to the category of outcome analyzed (economic welfare, equity, social inclusion, and environmental quality), a set of "policy variables" and a set of control variables:

$$
Y_{i, j}=\pi+\alpha O_{i, j}+\beta X_{i, j}+\delta Z_{i, j}+\epsilon_{i, j}
$$

where $Y$ is the reported $t$ statistic on the treatment variable, $O$ is the category of outcome analyzed $(O \in$ feconomic welfare, social inclusion, equity, environmental quality\}), $X$ is the set of policy variables, $Z$ is the set of control variables, and $\epsilon$ is the error term. The subscripts $i$ and $j$ denote the paper and estimate respectively. $\pi$ is the constant term.

$X$ includes variables that can provide useful insights into policy. These include details of the infrastructure intervention itself (type of construction, the transport mode, connection type). They also include a dummy variable for whether the regression underlying a given result allows for potential heterogeneous effects. ${ }^{27}$ Further, we include dummies relating to identification strategy (most notably, the use of IV estimation) in the set of "policy variables." This is because the comparison of results from papers that use an IV approach with those that do not can provide indirect insights into the placement decisions that policymakers undertake when selecting the locations to link with a transport corridor. Meanwhile, the set of control variables includes: dummies for World Bank regions, ${ }^{28}$ whether the paper has been published in a peer-reviewed academic journal, the year of publication, and the population density of the area where the study was undertaken. ${ }^{29}, 30$

Publication bias has long been a major concern for meta-analysts. Compared to studies that find small and insignificant effects, studies that find statistically significant results are more likely to be published because they are well received by researchers, reviewers, and editors. To control (and test for) publication bias, we use two approaches. First, we include as a control a dummy for whether the paper has been published in a

\footnotetext{
${ }^{27}$ In an earlier version of this paper, we also included among the "policy variables," dummies for whether a paper presents evidence of losers as well as winners, the markets that a paper highlights as important for the transmission of impacts, and whether the paper examines a role for complementary policies. However, as suggested by the referee, in this version of the paper we restrict our analysis to only a few policy variables to increase the overall degrees of freedom.

${ }^{28}$ For details of World Bank regions see http://www.worldbank.org/en/where-we-work.

${ }^{29}$ We thank the referee for suggesting the year of publication and population density control variables. We also estimated the models including two further variables suggested by the referee: namely, (a) the "time of intervention", which captures when the infrastructure was constructed, to test whether older projects have impacts which differ from those of more recent projects; and (b) the sample-period length, to differentiate between long- and short-term effects of transport infrastructure. However, neither of these variables were statistically significant. In a previous version of the paper, other control variables included the economic sector of the final outcome (aggregate, manufacturing, urban, rural); dummies for the income classification of the study country (low-income country, lower-middle-income country, upper-middle-income country, high-income country); a dummy for whether a paper contains an explicit theoretical motivation; and dummies for the unit of analysis (subnational regions, households, firms, countries).

${ }^{30}$ Appendix A provides a more detailed description of the policy and control variables that are included in the MRA.
} 
(a)

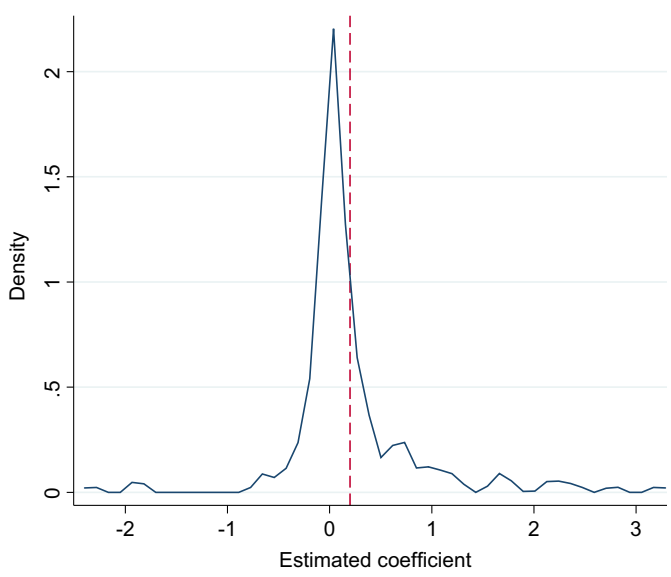

(b)

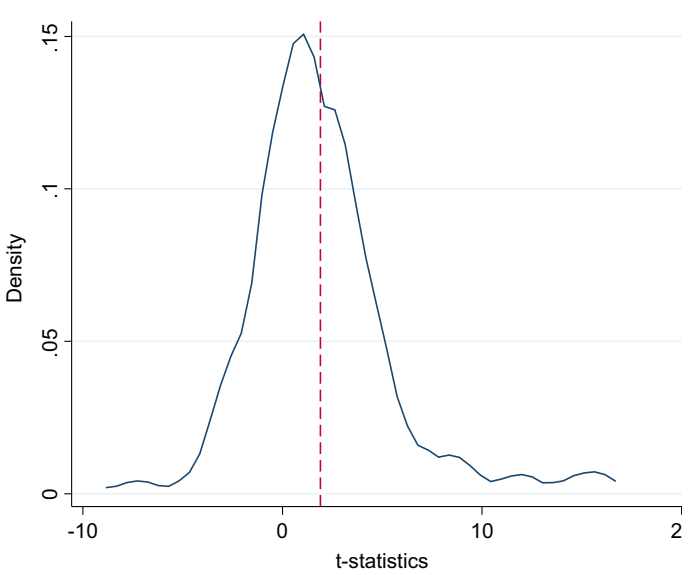

FIGURE 16 Estimated kernel densities of the estimated coefficients and $t$ statistics. The dashed vertical line marks the mean [Color figure can be viewed at wileyonlinelibrary.com]

peer-reviewed academic journal. Second, we employ the commonly used Egger test. ${ }^{31}$ This test regresses the standard normal deviate of a study effect estimate against its standard error. The null hypothesis is that there are no small-study effects. The estimated bias coefficient is 1.27 , with a standard error of 0.43 , giving a $p$ value of 0.003 . The test thus provides evidence for the presence of small-study effects: that is, there is a higher level of effect size in studies with smaller sample sizes.

Before turning to our estimation results, it is important to mention that there is a large amount of variance in the estimated impacts of large-scale transport infrastructure projects. Figure 16 presents the kernel densities of the estimated coefficients and the $t$ statistics. The vertical line shows that the distributions are skewed to the right, which is consistent with the fact that the mean paper finds a positive (beneficial) and significant impact.

\section{2 | Estimation results}

Table 3 presents the results from the estimation of three variants of Equation (1). Model 1 includes only dummy variables relating to the category of the outcome (WEBs) variable. Model 2 adds the set of "policy variables," X. Model 3 further includes the set of control variables, $Z$. For all three specifications, the dependent variable is transformed so that a positive value always indicates a beneficial outcome and a negative value a detrimental outcome. Standard errors are clustered by paper, thereby allowing for correlation in the error terms for observations extracted from the same paper. The discussion that follows focuses on the results from Models 1 and 3, where Model 3 is the preferred specification.

In Model 1, the estimated (unconditional) mean for the $t$ statistics related to the impacts of large transport infrastructure on economic welfare (which, given that economic welfare is the excluded category, corresponds to the constant term) is 2.355 , significant at the $1 \%$ level. Hence, on average, the literature finds that such infrastructure has a significant beneficial effect on economic welfare. The mean $t$ statistic for the transport infrastructure impact on equity is not significantly different from the estimated mean impact for economic welfare. Therefore, on average, the literature also finds that transport infrastructure has a significant beneficial effect on equity. By contrast, the $t$ statistics for the impacts on social inclusion and environmental quality are, on average, smaller than the average impact on welfare. For social inclusion, the impacts are smaller and/or less certain, but still, on average, beneficial; the net estimated coefficient on social

\footnotetext{
${ }^{31}$ The presence of publication bias is usually tested both graphically and formally. The graphical test uses the so-called funnel plot (Egger, Smith, Schneider, \& Minder, 1997; Stanley \& Doucouliagos, 2010), a scatter plot of the estimates (on the horizontal axis) against their precision (the inverse of the standard error; on the vertical axis). See Figure B.3 in Appendix B.
} 
TABLE 3 Meta-regression analysis: Dependent variable $=t$ stat (ordinary least squares estimation)

\begin{tabular}{|c|c|c|c|}
\hline Variables & $\begin{array}{l}\text { Model } 1 \\
\text { Outcomes only }\end{array}$ & $\begin{array}{l}\text { Model } 2 \\
\text { (1) + policy }\end{array}$ & $\begin{array}{l}\text { Model } 3 \\
\text { Full model }\end{array}$ \\
\hline Constant & $2.355^{*}(0.497)$ & $3.349^{* * *}(1.726)$ & $1.090(2.765)$ \\
\hline \multicolumn{4}{|l|}{ Outcome (omitted = economic welfare) } \\
\hline Equity & 1.481 (1.733) & $-0.626(1.049)$ & $-1.079(1.473)$ \\
\hline Social inclusion & $-0.893(0.880)$ & $0.0362(0.816)$ & $-0.384(0.969)$ \\
\hline Environment & $-17.61^{* * *}(2.506)$ & $-19.73^{*}(2.907)$ & $-21.54^{*}(2.982)$ \\
\hline \multicolumn{4}{|c|}{ Type of construction (omitted = new system) } \\
\hline Upgrade of system & & $0.681(1.492)$ & $3.892^{* * *}(2.046)$ \\
\hline Other construction & & $4.172^{* *}(1.597)$ & $5.286^{*}(1.966)$ \\
\hline \multicolumn{4}{|l|}{ Transport mode (omitted = road) } \\
\hline Rail & & $1.216(1.091)$ & $1.928(1.247)$ \\
\hline Other mode (waterway, bridge) & & $1.617^{* *}(0.732)$ & $4.942^{*}(1.726)$ \\
\hline \multicolumn{4}{|l|}{ Connection type (omitted = urban-urban) } \\
\hline Urban-rural & & $1.882^{* *}(0.864)$ & $3.523^{*}(1.113)$ \\
\hline Urban-gateway & & $1.081(1.303)$ & $2.077^{* * *}(1.322)$ \\
\hline \multicolumn{4}{|l|}{ Additional "policy variables" } \\
\hline $\begin{array}{l}\text { Heterogeneity (omitted = look for } \\
\text { heterogeneity) }\end{array}$ & & $-3.203^{* *}(1.594)$ & $-3.149^{* * *}(1.684)$ \\
\hline Identification strategy (omitted $=$ IV) & & $-0.950(1.236)$ & $-0.717(1.509)$ \\
\hline \multicolumn{4}{|c|}{ Region of study country (omitted $=$ North America) } \\
\hline Africa & & & $-3.415(2.124)$ \\
\hline East Asia Pacific & & & $-1.640(1.384)$ \\
\hline Western Europe & & & $0.651(1.889)$ \\
\hline Latin American and Caribbean & & & $2.033(2.491)$ \\
\hline Middle East and North Africa & & & $0.222(3.031)$ \\
\hline South Asia & & & $1.094(2.297)$ \\
\hline \multicolumn{4}{|l|}{ Other control variables } \\
\hline Journal article & & & $0.814(1.162)$ \\
\hline Year of publication & & & $0.186(0.136)$ \\
\hline Population density & & & $-0.00730^{* * *}(0.00396)$ \\
\hline Precision (1/SD) & $-0.00486(0.00311)$ & $-0.00409(0.00308)$ & $-0.00246(0.00382)$ \\
\hline Observations & 176 & 176 & 176 \\
\hline Adjusted R2 & 0.514 & 0.599 & 0.630 \\
\hline
\end{tabular}

Note: Robust standard errors are in parentheses and clustered at study level. $S D$, standard deviation.

Abbreviation: IV, instrumental variable; SD, standard deviation.

${ }^{*} p<.01$.

${ }^{* *} p<.05$.

${ }^{* * *} p<.1$.

inclusion is $1.462(=2.355-0.893)$. The less certain impacts on social inclusion could also be indicative of possible tradeoffs between boosting economic welfare and inclusion (job creation) through large transport infrastructure. In the case of environmental quality, the net coefficient is $-15.255(=2.355-17.61)$. Hence, on average, the effect of transport infrastructure on the environment is found to be detrimental. These findings are consistent with those reported in the descriptive analysis of the literature in Section 4.2.

For the full model (model 3), several "policy variables" are important. First, the type of construction and transport mode matters. Compared with construction of a new system, the reported impacts of upgrading a preexisting system and other types of construction (i.e., the building of a new link within a pre-existing system, and the upgrading of a pre-existing link in a pre-existing system) are significantly higher and/or more certain. Also, 
compared with roads and railways, the reported impacts of investments in other transport modes (waterways and bridges) are significantly larger and/or more certain. ${ }^{32}$

Second, the type of connection also matters. Compared with urban-urban connections, the literature reports (conditional on the other variables in the model) $t$ statistics that are, on average, significantly higher for investments that connect urban centers to rural areas or to international gateways such as ports, land border crossing points, and airports.

Third, consideration of heterogeneous impacts matters. We find that, relative to studies that do not consider heterogeneous impacts of transport infrastructure, studies that report evidence of heterogeneous effects along several different dimensions (such as across subnational geographic regions or across different sectors) tend to report significantly smaller $t$ statistics. This suggests that a failure to consider heterogeneous impacts is not only a gap in itself, but leads to an over-estimation of either the wider economic impacts of transport infrastructure and/ or the level of certainty surrounding these impacts.

Although the "policy variables" are of main interest, it is also worth commenting on the results for the control variables in Model 3. Thus, relative to North American countries, reported $t$ statistics are lower for African countries, albeit not significantly so. This suggests that the effects of transport infrastructure investment may be smaller and/or less certain in Africa than they are in North America. ${ }^{33}$ Despite the earlier reported Egger test result of small-study effects, we also find no significant evidence of a bias towards the publication of more favorable results. Hence, although the estimated coefficient on "Journal article" has the a priori anticipated positive sign, it is not statistically significant. The year of publication of a paper likewise has no significant influence on the $t$ statistics reported in that paper. ${ }^{34}$ Finally, the literature reports $t$ statistics that are, on average, smaller for countries/regions that are more densely populated, although we lack a clear explanation for why this might be the case.

\section{3 | Robustness check: Ordered-probit and random-effects models}

This section reports robustness checks using two different estimation methods: the ordered-probit model, and the random-effects model.

\subsection{1 | Ordered-probit model}

To estimate the ordered-probit model, we created a variable that takes a value of 0 for observations (results) that find a statistically significant beneficial impact at the $5 \%$ level, one for those that find an insignificant impact (despite positive or negative point estimates), and two for those that find a significant detrimental impact. This methodology has also recently been applied by De Groot et al. (2016), who provide evidence of wide heterogeneity among studies which estimate the strength of agglomeration externalities. To allow for the comparison of the results, we flip the signs of the coefficients. Compared to the OLS estimation which has a continuous scale from positive to negative estimates, the ordered-probit model allows for more distinction between insignificant and significant (beneficial and detrimental) estimated results.

\footnotetext{
${ }^{32}$ Although the number of papers that focus on waterways and bridges in our sample is small (see Figure $5 a$ ). The only paper in our sample that focuses on a bridge in terms of helping to create a transport corridor is Blankespoor et al. (2018), who examine the impacts of the Jamuna bridge in Bangladesh.

${ }^{33}$ In all our regressions, standard errors are clustered at the study level, but our units of observation are results, with the possibility of multiple results per study. Table A.3 in Appendix A presents the number of results and countries per region dummy. As can be seen, the number of results that underpin the estimation of the Western Europe, Latin American and Caribbean, and Middle East and North Africa region dummies is, in each case, <15. We find, however, that when we combine these three dummies into one, our overall results are nearly identical.

${ }^{34}$ Following a suggestion by the editor and an anonymous referee, we also looked at the importance of journal quality (measured by a journal's impact factor). The results show that, on average, $t$ statistics reported from studies published in well cited journals are higher, but the coefficient is not significant.
} 


\subsection{2 | Random-effects model}

Following Jeppesen et al. (2002), we also estimate a random effects panel model. There are four main reasons to possibly favor the random effects model over the fixed effects model. First, the fixed effects model assumes that all papers have been conducted under similar conditions and the only difference between them is their power to detect a beneficial or detrimental impact. This assumption could be violated for our data since the Higgins statistic $\left(I^{2}=98 \%\right)$ provides evidence of clear heterogeneity. Second, the random-effects meta-regression can be considered as an extension to the fixed-effects meta-regression that allows for residual heterogeneity. Third, the random effects model will reflect the fact that all studies included in the analysis are assumed to be a random sample of all possible studies that meet the inclusion criteria for our literature review. Fourth, the random effects model assumes that the estimated coefficient is randomly, normally distributed across studies. ${ }^{35}$ Specifically, this model is expressed as follows:

$$
\hat{\beta_{i, j}}=u_{i}+\alpha O_{i, j}+\beta X_{i, j}+\delta Z_{i, j}+\epsilon_{i, j}
$$

where $\hat{\beta_{i, j}}$ is the $j$ estimated coefficient reported in paper $i$, since we have adopted a multiple-estimate-per-study approach, and $u_{i}$ is the random paper effect. ${ }^{36}$ The rest of the notation is as in Equation (1).

Equation (2) is rarely estimated because of heteroskedasticity (Stanley \& Doucouliagos, 2010). To obtain efficient estimates we estimate its weighted least squares (WLS) version, which divides Equation (2) by the standard error. The corresponding meta-regression model is expressed as follows:

$$
\hat{t_{i, j}}=u_{i} \frac{1}{s e_{j}}+\alpha O_{i, j} \frac{1}{s e_{j}}+\beta X_{i, j} \frac{1}{s e_{j}}+\delta Z_{i, j} \frac{1}{s e_{j}} \epsilon_{i, j}
$$

where $t_{i, j}$ is the standardized impact estimate, and $s e_{j}$ the standard error of estimate $j$. The main difference between the random effects and our earlier OLS model is that the latter gives the same weight to the between- and withinpaper variation, whereas the random effects model accounts for differences between individual study effects (which is especially relevant in our case where the effects across the studies are heterogeneous).

The results from the estimated ordered-probit and random effects models are presented in Table B1, Appendix B. Estimates for all Models 1-3) are qualitatively comparable. To save space we only report results of Model 3 (i.e., the full model which includes final outcomes, policy variables, and the control variables). To facilitate comparison, we also report the results of Model 3 as estimated using OLS again. Several results emerge from this robustness analysis.

First, most of our results are consistent with the OLS regression of the $t$ statistics (i.e., with the results reported in Table 3). The main exceptions are with the ordered-probit model where, unlike with the OLS and random effects models, the types of locations being linked appears not to matter and where estimated results for countries in Latin America and the Caribbean tend to produce evidence of impacts that differ significantly from those of North America.

Second, columns four and five of Table B1 show that finding a beneficial and detrimental impact on "environmental quality" in circumstances when the average impact on economic welfare is significantly positive is, respectively, less and more likely. These probabilities decrease by 3.92 percentage points for finding a beneficial impact and increase by 2.74 percentage points for finding a detrimental impact on "environmental quality"confirming a prevailing significant tradeoff in boosting economic welfare and protecting the environment.

\footnotetext{
${ }^{35}$ Recall that the fixed-effect model assumes that the true effect size for all studies is identical, and the only reason the effect size varies across studies is the sampling error (error in estimating the effect size). However, the random-effects model's goal is not to estimate one true effect size, but to estimate the mean of a distribution of effects of possibly varying size. Since each study provides information about a specific effect size, we want to be sure that all these effect sizes are represented in the summary estimate.

${ }^{36}$ This is a slightly different approach to the Jeppesen et al. (2002) framework, where $u_{i}$ corresponds to the random author effect.
} 
Third, columns four and five of Table B1 further show that the probability of finding a significantly beneficial (detrimental) impact of "upgrade of system" and "other construction"-that is either the building of a new or upgrading of an existing link within a pre-existing system-relative to "new construction system"-the omitted category-significantly increases (decreases) by 0.31 ( 0.21 for other construction) and 0.23 (0.16 for other construction) percentage points.

Fourth, the probability of finding a beneficial (detrimental) impact in countries/regions that are more densely populated significantly increases (decreases) by $0.0008(0.0005)$ percentage points.

\section{6 | CONCLUSION}

This paper has presented a quantitative review and meta-regression analysis of studies estimating the wider economic impacts of large-scale transport infrastructure projects. The primary objective was to help policymakers better solve the problem of optimally designing the intervention package for a transport corridor. While anchored in the trunk transport infrastructure, such an intervention package also includes a set of complementary interventions - that is policies and institutional reforms - that help amplify the net WEBs of the trunk infrastructure by boosting average impacts and mitigating trade-offs. With this objective, the paper yields several important insights.

First, policymakers must account for potential trade-offs in different development outcomes and across different locations and (sub)sets of economic actors when designing a transport corridor package. This follows from two key findings of the literature review:

- While for the wider economic outcomes of economic welfare, equity and social inclusion, average estimated impacts tend to be beneficial, for environmental quality they tend to be detrimental.

- Even for economic welfare, equity and social inclusion, while the average impacts may be beneficial, considerable heterogeneity in these impacts can exist. In some cases, this heterogeneity may involve subnational locations or segments of the population that lose in absolute terms.

The existence and nature of these trade-offs should drive the choice of complementary interventions that accompany the construction of the trunk transport infrastructure itself-such as supporting or redistribution policies for the identified losers from trunk infrastructure investments.

Second, the set of complementary policies and institutions that form part of the optimal transport corridor package could depend on the nature of the transport infrastructure intervention that forms the backbone of that package. This follows, for example, from our meta-regression finding that estimated impacts depend on the type of locations that are being connected. Although not necessarily considered by the surveyed empirical literature, it is reasonable to expect that the set of complementary policies and institutions that enter into the optimal corridor package will depend on two aspects: preintervention conditions (imperfections) in product, capital, labor, and land markets; and the initial endowments of different locations and economic agents that are affected by the transport intervention (see ADB et al., 2018; Melecky, Roberts, and Sharma, 2019).

Third, the placement and design of the transport infrastructure itself matters for the net WEBs a transport corridor package can achieve. Not only does this follow from the finding that the size and certainty of estimated impacts depend on the type of locations being connected, but our meta-regressions also reveal that the mode of transportation matters. Perhaps surprisingly, within our sample, the estimated WEBs of waterway and bridge projects are larger/more certain than those of road projects. However, this finding must be interpreted extremely carefully, given that there are only three papers in our sample that looked at the impact of a bridge or waterway. This implies that the finding may not be very generalizable. 
In addition to these three main policy insights, our literature review highlights many important areas where further research is needed to better inform the optimal design of transport corridor packages. The five most pressing areas are as follows.

First, much more research is required to clarify the nature and extent of trade-offs. In particular, the impacts of large transport projects on measures of economic welfare has been studied extensively. However, the evidence of impacts on other types of outcome is more limited and less rigorous. A prime example is the impact on economic resilience-defined as the resilience of economic agents to various types of shock, rather than the resilience of the transport infrastructure itself. Although environmental impacts are better studied, the literature is not as advanced in its consideration of endogeneity problems as the literature focusing on economic welfare. Research to study the impact of a single transport project on the outcomes of economic welfare, social inclusion, equity, and environmental quality simultaneously would be particularly useful. ${ }^{37}$ This would provide more direct insight into the nature of the trade-offs between these outcomes, rather than the indirect inference that we make by looking across papers. Likewise, more research is required to explore trade-offs across different segments of the population for each development outcome.

Second, the importance of trade-offs points to the importance of complementary policies and institutional reforms. The literature has done little to analyze the role of other interventions in shaping the impacts of transport infrastructure. Hence, we find virtually no evidence on the appropriate design of complementary interventions in different circumstances. An important technical reason for this neglect may be that the literature has been striving to cleanly identify the impacts of the transport infrastructure itself. This requires isolating infrastructure impacts from the impacts of other factors, including other policy changes and reforms. While this is desirable from the perspective of academic rigor, the cost may be policy relevance.

Third, in principle, a promising way to study trade-offs and the interaction of transport infrastructure investments with other policies could be through structural general equilibrium modelling. Such modelling also lends itself to the potential ex ante evaluation of proposed transport corridor packages. Our review shows that the literature is dominated by RF estimations. Perhaps there is some skepticism about structural general equilibrium modelling because it assumes that the model structure is correct at capturing the factual transmission mechanisms and functional forms when linking policy interventions to outcomes, as well as when drawing conclusions about the multiple and second-round impacts. If the model structure is correct, structural general equilibrium models could be the best tool to use. But if incorrect, it could be an inferior tool for policy decision making. By contrast, standard RF, DID estimation is purely empirical and requires no knowledge of the underlying mechanisms. As such, RF estimation is generally seen as being more flexible and reliable. But the flexibility comes at the cost of partial equilibrium estimates with little consideration of second-round effects. Further research is required to improve the quality and accuracy of structural general equilibrium models, and the identification and comprehensiveness of RF regressions.

Fourth, the literature has been mainly concerned with estimating the impacts of road projects. When it has focused on the evaluation of rail projects, it has mainly been on historical projects. Hence, more research is required on the evaluation of more modern rail projects, including both high-speed rail and freight railway corridors such as those that India is currently constructing. More research is also required on the impacts of multimodal transport projects, especially because multimodal freight movements are likely to be key to the design of many transport corridors in the future.

Fifth and finally, the literature that we surveyed covers a wide variety of countries. Nevertheless, much of the research has focused on just three countries: China, India, and the United States. Therefore, the literature would benefit from research on other countries to gain insights into impacts in different country contexts.

\footnotetext{
${ }^{37}$ For an attempt at research along these lines see Melecky et al. (2018) and Melecky et al. (2019).
} 


\section{ACKNOWLEDGEMENTS}

The authors thank the editor Steven Brakman and one anonymous referee. They also thank Esther Bartl for excellent research support, as well as Martin Rama, Arjun Goswami, Jay Menon, Akio Okamura, Takayuki Urade, and Duncan Overfield for suggestions and comments on earlier drafts of the paper. They likewise thank Marianne Fay, Bill Maloney, Uwe Deichmann, and Somik Lall for excellent comments on the paper at an Authors' workshop for the World Bank's South Asia Region Economic Corridors Flagship report held in June 2017. The findings, interpretations, and conclusions expressed in this paper are entirely those of the authors. They do not necessarily represent the views of the International Bank for Reconstruction and Development/World Bank and its affiliated organizations, or those of the Executive Directors of the World Bank or the governments they represent.

\section{ORCID}

Mark Roberts (D) http://orcid.org/0000-0001-7905-1107

\section{REFERENCES}

Alder, S. (2015). Chinese roads in India: The effect of transport infrastructure on economic development (Working paper). University of North Carolina, Chapel Hill.

Alder, S., Roberts, M., \& Tewari, M. (2017). The effect of transport infrastructure on India's urban and rural development. Unpublished manuscript, University of North Carolina, Chapel Hill.

Ali, R., Barra, A. F., Berg, C. N., Damania, R., Nash, J., \& Russ, J. (2015). Transport infrastructure and infrastructure and welfare: An application to Nigeria (Policy Research Working Paper No. 7271). Washington, D.C.: The World Bank.

Arman, S. A., Manesh, A. S., \& Izady, A. T. (2015). Design of a CGE model to evaluate investment in transport infrastructures: An application for Iran. Asian Economic and Financial Review, 5(3), 532-545.

Aschauer, D. A. (1989). Is public expenditure productive? Journal of Monetary Economics, 23(2), 177-200.

Asian Development Bank (ADB), Department for International Development (DFID), Japan International Cooperation Agency (JICA), \& the World Bank (WB) (2018). The WEB of Transport Corridors in South Asia. Washington, D.C.: The World Bank.

Asturias, J., García-Santana, M., \& Ramos, R. (2018). Competition and the welfare gains from transportation infrastructure: Evidence from the golden quadrilateral of India. Journal of the European Economic Association, https://doi.org/10.1111/ jeea.12167 Advance online publication.

Atack, J., \& Margo, R. A. (2011). The impact of access to rail transportation on agricultural improvement: The American midwest as a test case, 1850-1860. Journal of Transport and Land Use, 4(2), 5-18.

Banerjee, A., Duflo, E., \& Qian, N. (2012). On the road: Access to transportation infrastructure and economic growth in China (NBER Working Paper No. 17897). Cambridge, M.A.: National Bureau of Economic Research, Inc.

Barber, C. P., Cochrane, M. A., Souza, C. M., \& Laurance, W. F. (2014). Roads, deforestation, and the mitigating effect of protected areas in the Amazon. Biological Conservation, 177(C), 203-209.

Baum-Snow, N. (2007). Did highways cause suburbanization? The Quarterly Journal of Economics, 122(2), $775-805$.

Baum-Snow, N., Brandt, L., Henderson, J.V., Turner, M.A., \& Zhang, Q. (2016). Highways, market access and urban growth in China (SERC Discussion Paper No. 0200). London: Spatial Economics Research Centre, London School of Economics.

Baum-Snow, N., Henderson, J. V., Turner, M. A., Zhang, Q., \& Brandt, L. (2018). Does investment in national highways help or hurt hinterland city growth? Journal of Urban Economics, 1-19. https://doi.org/10.1016/j.jue.2018.05.001

Berg, C. N., Deichmann, U., Liu, Y., \& Selod, H. (2017). Transport policies and development. The Journal of Development Studies, 53(4), 465-480.

Blankespoor, B., Emran, M. S., Shilpi, F., \& Xu, L. (2018). Bridge to big push or backwash? Market integration, reallocation, and productivity effects of Jamuna bridge in Bangladesh (Policy Research Working Paper No. 8508). Washington, D.C.: The World Bank.

Bosker, M., Deichmann, U., \& Roberts, M. (2018). Hukou and highways the impact of China's spatial development policies on urbanization and regional inequality. Regional Science and Urban Economics, 71(2018), 91-109.

Bosker, M., \& Garretsen, H. (2010). Trade costs in empirical new economic geography. Papers in Regional Science, 89(3), 485-511.

Buys, P., Deichmann, U., \& Wheeler, D. (2006). Road network upgrading and overland trade expansion in Sub-Saharan Africa (Policy Research Working Paper No. 4097). Washington, D.C.: The World Bank. 
Cantos, P., Gumbau-Albert, M., \& Maudos, J. (2005). Transport infrastructures, spillover effects and regional growth: Evidence of the Spanish case. Transport Reviews, 25(1), 25-50.

Cao, J., Liu, X. C., Wang, Y., \& Li, Q. (2013). Accessibility impacts of China's high-speed rail network. Journal of Transport Geography, 28, 12-21.

Card, D., Kluve, J., \& Weber, A. (2010). Active labour market policy evaluations: A meta-analysis. The Economic Journal, 120(548), F452-F477.

Chandra, A., \& Thompson, E. (2000). Does public infrastructure affect economic activity? Regional Science and Urban Economics, 30(4), 457-490.

Chen, M., Pan, A., Malik, V. S., \& Hu, F. B. (2012). Effects of dairy intake on body weight and fat: A meta-analysis of randomized controlled trials. The American Journal of Clinical Nutrition, 96(1), 735-747.

Conde, D. A. (2008). Road impact on deforestation and Jaguar habitat loss in the Mayan forest (Doctoral dissertation). Duke University.

Costinot, A., Donaldson, D., \& Komunjer, I. (2011). What goods do countries trade? A quantitative exploration of Ricardo's ideas. The Review of Economic Studies, 79(2), 581-608.

Coşar, A. K., \& Demir, B. (2016). Domestic road infrastructure and international trade: Evidence from Turkey. Journal of Development Economics, 118, 232-244.

Cropper, M., Puri, J., \& Griffiths, C. (2001). Predicting the location of deforestation: The role of roads and protected areas in North Thailand. Land Economics, 77(2), 172-186.

Damania, R., \& Wheeler, D. (2015). Road improvement and deforestation in the Congo basin countries (Policy Research Working Paper No. 7274). Washington, D.C.: The World Bank.

Dasgupta, S., \& Wheeler, D. (2016). Minimizing ecological damage from road improvement in tropical forests (Policy Research Working Paper No. 7826). Washington, D.C.: The World Bank.

Donaldson, D. (2018). Railroads of the Raj: Estimating the impact of transportation infrastructure. American Economic Review, 108(4-5), 899-934.

Donaldson, D., \& Hornbeck, R. (2016). Railroads and American economic growth: A "Market Access" approach. The Quarterly Journal of Economics, 131(2), 799-858.

Eaton, J., \& Kortum, S. (2002). Technology, geography, and trade. Econometrica, 70(5), 1741-79.

Egger, M., Smith, G. D., Schneider, M., \& Minder, C. (1997). Bias in meta-analysis detected by a simple, graphical test. British Medical Journal, 316(7109), 246-320.

Faber, B. (2014). Trade integration, market size, and industrialization: Evidence from China's national trunk highway system. Review of Economic Studies, 81(3), 1046-1070.

Fogel, R. W. (1964). Railroads and American economic growth: Essays in econometric history. Baltimore: Johns Hopkins University Press.

Fujita, M., Krugman, P. R., \& Venables, A. J. (1999). The spatial economy: Cities, regions and international trade. Cambridge, M.A.: MIT Press.

Gertler, P. J., Gonzalez-Navarro, M., Gracner, T., \& Rothenberg, A. D. (2014). The role of road quality investments on economic activity and welfare: Evidence from Indonesia's highways. Unpublished manuscript.

Ghani, E., Goswami, A. G., \& Kerr, W. R. (2016). Highway to success: The impact of the golden quadrilateral project for the location and performance of Indian manufacturing. The Economic Journal, 126(591), 317-357.

Ghani, E., Goswami, A. G., \& Kerr, W. R. (2017). Highways and spatial location within cities: Evidence from India. The World Bank Economic Review, 30(Suppl 1), S97-S108.

Gibbons, S., Lyytikäinen, T., Overman, H. G., \& Sanchis-Guarner, R. (2019). New road infrastructure: The effects on firms. Journal of Urban Economics, 110, 35-50.

De Groot, H. L. F., Poot, J., \& Smit, M. J. (2016). Which agglomeration externalities matter most and why? Journal of Economic Surveys, 30(4), 756-782.

Haines, M. R., \& Margo, R. A. (2006). Railroads and local economic development: The United States in the 1850s (NBER Working Paper No. 12381). Cambridge, M.A.: National Bureau of Economic Research, Inc.

Havranek, T., Irsova, Z., Janda, K., \& Zilberman, D. (2015). Selective reporting and the social cost of carbon. Energy Economics, 51(C), 394-406.

Herrendorf, B., Schmitz, J. A., Jr, \& Teixeira, A. (2012). The role of transportation in US economic development: 1840-1860. International Economic Review, 53(3), 693-716.

Higgins, J. P., Thompson, S. G., Deeks, J. J., \& Altman, D. G. (2003). Measuring inconsistency in meta analyses. BMJ, 327(7414), 557-560.

Jedwab, R., \& Storeygard, A. (2017). The average and heterogeneous effects of transportation investments: Evidence from SubSaharan Africa 1960-2010 (IDEAS Working Paper Series from RePEc). Department of Economics, Tufts University.

Jeppesen, T., List, J. A., \& Folmer, H. (2002). Environmental regulations and new plant location decisions: Evidence from a meta-analysis. Journal of Regional Science, 42(1), 19-49. 
Khanna, G. (2016). Road oft taken: The route to spatial development. Available at SSRN 2426835.

Kiel, J., Betancor, O., Fiedler, R., Hernández, A., Kretschmann, L., \& Soccoro, P. (2014). Deliverable 3.2 analysis of models and their results from transport infrastructure project. Report for: European Commission Directorate-General for Research and Innovation. Retrieved from https://www.i-c-eu.eu/deliverables/I-C-EU_WP3_D3.2.pdf

Krugman, P. (1991a). Increasing returns and economic geography. Journal of Political Economy, 99(3), 483-499.

Krugman, P. (1991b). Geography and trade. Cambridge, M.A: MIT Press.

Laird, J. J., \& Venables, A. J. (2017). Transport investment and economic performance: A framework for project appraisal. Transport Policy, 56(May), 1-11.

Martincus, C. V., Carballo, J., \& Cusolito, A. (2016). Routes, exports, and employment in developing countries: Following the trace of the Inca Roads. Unpublished manuscript, Inter-American Development Bank, Washington, D.C.

Melecky, M., Roberts, M., \& Sharma, S. (2019). The wider economic benefits of transport corridors: A policy framework and illustrative application to the China-Pakistan economic corridor. Cambridge Journal of Regions, Economics and Society, 12(1), 17-44.

Melecky, M., Sharma, S., \& Subhash, H. (2018). Wider economic benefits of investments in transport corridors and the role of complementary policies (Policy Research Working Paper No. 8350). Washington, D.C.: The World Bank.

Michaels, G. (2008). The effect of trade on the demand for skill: Evidence from the interstate highway system. Review of Economics and Statistics, 90(4), 683-701.

Nist, N. I. S. T. (2006). SEMATECH e-handbook of statistical methods. US Department of Commerce.

Pereira, R. M., Hausman, W. J., \& Pereira, A. M. (2014). Railroads and economic growth in the Antebellum United States (Working Paper No. 153). Williamsburg: Department of Economics, College of William and Mary.

Pfaff, A., Robalino, J., Walker, R., Aldrich, S., Caldas, M., Reis, E., ... Kirby, K. (2007). Road investments, spatial spillovers, and deforestation in the Brazilian Amazon. Journal of Regional Science, 47(1), 109-123.

Redding, S. J., \& Turner, M. A. (2014). Transportation costs and the spatial organization of economic activity (NBER Working Paper No. 20235). Cambridge, M.A.: National Bureau of Economic Research, Inc.

Revoltella, D., Brutscher, P. B., Tsiotras, A., \& Weiss, C. T. (2016). Linking local business with global growth opportunities: The role of infrastructure. Oxford Review of Economic Policy, 32(3), 410-30.

Roberts, M., Deichmann, U., Fingleton, B., \& Shi, T. (2012). Evaluating China's road to prosperity: A new economic geography approach. Regional Science and Urban Economics, 42(4), 580-94.

Roberts, M., Melecky, M., Bougna, T., \& Xu, Y. (2017). Transport corridors and their wider economic benefits: A critical review of the literature (Policy Research Working Paper No. 8302). Washington, D.C., The World Bank.

Rozenberg, J., Briceno-Garmendia, C., Lu, X., Bonzanigo, L., \& Moroz, H. (2017). Improving the resilience of Peru's road network to climate events (Policy Research Working Paper No. 8013). The World Bank.

Stanley, T. D., \& Doucouliagos, H. (2010). Picture this: A simple graph that reveals much ado about research. Journal of Economic Surveys, 24(1), 170-191.

Stanley, T. D., \& Jarrell, S. B. (1989). Meta-regression analysis: A quantitative method of literature surveys. Journal of Economic Surveys, 3(2), 161-170.

Straub, S. (2011). Infrastructure and development: A critical appraisal of the macro-level literature. Journal of Development Studies, 47(5), 683-708.

Vickerman, R. (2007). Cost-benefit analysis and large-scale infrastructure projects: State of the art and challenges. Environment and Planning B: Planning and Design, 34(4), 598-610.

Volpe Martincus, C., \& Blyde, J. (2013). Shaky roads and trembling exports: Assessing the trade effects of domestic infrastructure using a natural experiment. Journal of international economics, 90(1), 148-161.

Weinhold, D., \& Reis, E. (2008). Transportation costs and the spatial distribution of land use in the Brazilian Amazon. Global Environmental Change, 18(1), 54-68.

How to cite this article: Roberts M, Melecky M, Bougna T, Xu Y. Transport corridors and their wider economic benefits: A quantitative review of the literature. J Regional Sci. 2019;1-42.

https://doi.org/10.1111/jors.12467 


\section{APPENDIX A: TAGGING SYSTEM AND DATA}

\section{Detailed description of the tagging system}

A tagging system was developed to facilitate the systematic collection of data from papers selected for inclusion in the literature review. This system covers 30 variables grouped into five categories: (a) publication details; (b) intervention details; (c) methodology; (d) results; and (e) additional. The variables under each category are listed below:

- Publication details: Title of paper, author(s), publication year, publication type, title of journal/working paper series, journal quality, country, keywords, key findings.

- Intervention details: Transport mode, type of construction, connection type, time of intervention.

- Methodology: Motivating theory, type of analysis, methodology, unit of analysis, sector, sample-period, outcome variable, treatment variable, identification strategy.

- Results: Significant impact (5\%), estimated impact sign, whether a paper looks for heterogeneity, heterogeneity factor, whether there are winners and losers.

- Additional: Complementary intervention, markets, and any additional notes that might be relevant to the analysis.

To help ensure the consistency and comparability of the data extracted from papers, the values of many variables were restricted to a set of options, which are discussed in detail below. Data were collected for each result of interest reported in a paper. Hence, if a paper presents results for two different outcome variables of interest, data were collected for both results. Thus, the final data set that results from the application of the tagging system contains $N=\sum_{i=1}^{P} r_{i}$ observations, where $r_{i}$ indexes the number of results extracted from paper $i$ and there are $P$ papers in total.

\section{Publication details}

- Title of paper

- Author(s): All listed authors of the paper.

- Publication year: For journal papers, the year of publication of the issue of the journal in which the paper appears. For working papers, the year of publication for the version from which information was extracted. This is typically the latest version available online but does not rule out subsequently updated versions that have been published. For unpublished manuscripts that were downloaded from the personal websites of authors and other sources, the year of publication was taken from the date on the manuscript.

- Publication type: Journal paper, working paper, book chapter, unpublished manuscript.

- Title of journal/working paper series: only recorded for journal papers and working papers published in a recognized series.

- Journal quality: RePEc simple impact factor (only recorded for papers published in peer-reviewed journals).

- Country: Country or countries studied in the paper. Where the paper presents analysis for an entire region (such as Africa), the name of the region is recorded.

- Keywords: Keywords stated by the author(s). In cases in which no keywords were available, the authors/RAs determined based on the study.

- Key findings: Summary of main findings based on the abstract of the paper. 


\section{Intervention details}

- Transport mode: Describes the mode of transportation to which the intervention relates. Values of the variable were restricted to five options: road, rail, waterway, bridge, and intermodal. Intermodal refers to transport infrastructure investments that combine more than one mode as part of an integrated package. In cases where the paper evaluates the impacts of transport infrastructure that covers multiple modes, but these modes are not necessarily part of an integrated system, all relevant modes were tagged. ${ }^{38}$

- Type of construction: Indicates whether the infrastructure investment represents new construction or an upgrade of pre-existing infrastructure, as well as its coverage as an individual link or an entire system. Values of the variable were restricted to five options: system-new construction, system-upgrade, individual link-new construction, individual link-upgrade, existing-other. There are nine papers tagged existing-other, in which the existing infrastructures were studied and affected by external factors other than upgrading or newly built, such as earthquake and deforestation (e.g., Barber, Cochrane, Souza, \& Laurance, 2014; Volpe Martincus \& Blyde, 2013). One or more options could be selected.

- Connection type: The types of location that the transport infrastructure connects. Values are restricted to four options: urban-urban, urban-rural, urban-gateway, rural-rural. One or more options could be selected. Gateway refers to an international port, land border, or airport that provides a gateway to international markets.

- Time of intervention: Refers to the years during which the infrastructure was constructed. When it is unclear from the study, the value was recorded as missing.

\section{Methodology}

- Motivating theory: Whether the paper includes an explicit theoretical model or discussion to motivate and/or support the design of the empirical analysis. Values are restricted to two options: yes and no.

- Type of analysis: Restricted to two options: ex ante and ex post. Ex ante refers to the evaluation of a transport infrastructure project before it has been undertaken, while ex post refers to the evaluation of a project after it has been implemented based on observed outcomes.

- Methodology: The empirical methodology employed in the estimation of the impacts of the transport infrastructure investment. Values are restricted to four options: reduced-form (RF); structural model - estimation + calibration; structural model - system estimation; computable general equilibrium. "Structural model - estimation + calibration" refers to the estimation of impacts based on a fully specified structural model where values of the parameters of the model are assigned based on a mixture of estimation and calibration techniques. ${ }^{39}$ If the methodology is none of the available options, it is marked in variable "note."

- Unit of analysis: The type of data used in the empirical analysis to generate a result. Values are restricted to five options: country, countries, subnational regions, micro-data-households, micro-data-firms. One or more options could be selected.

- Sector: Records whether, for the given unit of analysis, the estimated impact refers to an aggregate-level or sectoral level outcome. Values restricted to five options: aggregate, agriculture, manufacturing, services, urban, rural.

- Sample-period: Sample-period used in estimation of impacts and/or model calibration.

- Outcome variable: Records the outcome variable that the analysis estimates the impacts of the transport infrastructure on. This outcome variable can be either a final outcome-in which case, it refers to a wider economic benefits (WEB) variable-or an intermediate outcome. Values for an intermediate outcome are restricted

\footnotetext{
${ }^{38}$ This is the case, for example, for papers that consider the impacts of a general measure of the stock of transportation infrastructure (e.g., Cantos, Gumbau-Albert, \& Maudos, 2005) or that consider the impacts of proximity to corridors that have historically been the target of multiple types of transport infrastructure investment (e.g., Banerjee et al., 2012).

${ }^{39}$ Roberts et al. (2012) is an example of a paper that was tagged as "structural model - estimation + calibration."
} 
to the following options: trade, population, population growth, migration, land value, assets, productivity, foreign direct investment (FDI), diversification, firm entry/exit, export entry, market access, agglomeration, structural change, congestion, allocative efficiency, price. Values for a final outcome are restricted to the following options: welfare (assets), welfare (consumption growth), welfare (consumption), welfare (income growth), welfare (nominal income), welfare (real income), welfare (income volatility), environment (deforestation), environment ( $\mathrm{CO}_{2}$ emissions), environment (others), equity (overall income distribution), equity (spatial distribution), poverty, social inclusion (education), social inclusion (gender), social inclusion (jobs), social inclusion (other), resilience (marginal loss), resilience (food security), resilience (access). When impacts on several outcomes are reported in a study, each outcome is recorded as a separate observation.

- Treatment variable: Refers to how the transport infrastructure investment is incorporated into the empirical model. For example, when the model includes a dummy variable with one for exposure to the transport infrastructure and zero for otherwise, the value is recorded as discrete. When the investment is incorporated as an independent variable using the distance to the location of the infrastructure, the value is recorded as continuous. Values are restricted to seven options: discrete, continuous, investment size in \$, change in travel time, change in transport cost, quality upgrade, market access. In cases where the available options do not describe how the investment is incorporated into the model, the closest option was selected.

- Identification strategy: Refers to the type of strategy used in the estimation to address potential issues of endogeneity (most notably, issues of endogenous placement of the transport infrastructure). Values restricted to the following options: difference-in-difference, double difference-in-difference, IV/2SLS, GMM- Lag, matching, placebo, heteroskedasticity-based identification, other, or none.

\section{Results}

- Significant impact (5\%): Whether the estimated impact of treatment variable on outcome variable is statistically significant at the $5 \%$ level. Values restricted to two options: yes and no. Where an estimate of impact is based on counterfactual simulation using either a CGE or structural model and statistical significance is therefore not reported, the variable is coded yes if the author(s) refer to it as being, for example, "large," "important," or "significant." Otherwise, it is coded as no.

- Estimated impact sign: Refers to whether the estimated impact of treatment variable on outcome variable is "beneficial" or "detrimental," where beneficial (detrimental) indicates that the impact is positive (negative) from a broader social welfare perspective. Note that "beneficial" does not necessarily indicate that the estimated coefficient on treatment variable is positive. For example, if the outcome variable is a measure of deforestation and the treatment variable is discrete, then a positive estimated coefficient would represent a detrimental impact. Values are restricted to two options: beneficial and detrimental.

- Look for heterogeneity: Whether the analysis tests for variations in the impact of the infrastructure across any dimension. Values are restricted to two options: yes (tests for heterogeneity) and no.

- Heterogeneity factor: Refers to the dimension across which the impact varies. Values restricted to the following options: geographic, urbanization level, sector, geo-sector, land, protected area, crop type, labor, temporal, gender, literacy, age (e.g., worker age, population age), market size, firm size, infrastructure type, other. One or more options could be selected. When the dimension was found not to match with any of the options available, the closest option was selected. Observations for which look for heterogeneity = no were coded as missing.

- Winners and losers: Whether the infrastructure is estimated to result in absolute losses for certain geographic regions or groups of economic actors alongside the presence of winners. Values restricted to two options: yes (evidence of losers) and no. 


\section{Additional}

- Complementary intervention: Records whether the paper contains any explicit analysis of the role of complementary interventions in influencing the impact of treatment variable(s) on outcome variable(s). Values restricted to two options: yes and no.

- Markets: Records whether the paper discusses imperfections or features of the operation of particular market(s) as potentially influencing the estimated impacts obtained. If the paper does contain such a discussion, the market is recorded. Values are restricted to the following options: land, labor, capital, finance, goods and services, none, or not discussed. Selection of more than one market was allowed.

- Note: Any additional information that might be relevant for the quantitative analysis performed for the literature review.

The distribution of papers by country is presented in Table A1.

TABLE A1 Distribution of papers by country

\section{Countries}

Australia

1

Bangladesh

3

Bolivia

Brazil

Cameroon

Chile

China

Colombia

Democratic Republic of Congo

Egypt

Ethiopia

France

Germany

India

Indonesia

Iran

Mexico

Netherlands

Nigeria

Papua New Guinea

Peru

Spain

Switzerland

Tanzania

Thailand
1

6

1

1

14

2

2

1

2

1

1

11

2

1

5

1

2

3

1

4

1

1

1

(Continues) 
TABLE A1 (Continued)

\begin{tabular}{lc} 
& \# of studies \\
\hline Turkey & 1 \\
\hline United Kingdom & 3 \\
\hline United States & 15 \\
\hline Uganda & 1 \\
\hline Vietnam & 1 \\
West Bank and Gaza & 2 \\
\hline Region & 1 \\
\hline Africa & 3 \\
\hline Cameroon, Central Africa Republic, Ethiopia & 1 \\
\hline Mexico/Belize/Guatemala & 1 \\
\hline Sub-Saharan Africa & 1 \\
\hline West-Africa & 1 \\
\hline
\end{tabular}

Note: Several papers have studied more than one country, so the sum of counts in the table exceeds the total number of papers. Africa refers to cross-country studies that investigate the effects in many African countries.

TABLE A2 Studies included in the meta-analysis

\begin{tabular}{|c|c|c|c|}
\hline Study & Publication & $N$ & Share (\%) \\
\hline Holl (2004) & Regional Science and Urban Economics & 2 & 0.59 \\
\hline Agrawal, Galasso and Oettl (2017) & The Review of Economics and Statistics & 1 & 0.3 \\
\hline Ahlfeldt and Feddersen (2010) & Working paper & 3 & 0.89 \\
\hline Alder (2016) & Working paper & 2 & 0.59 \\
\hline Alder, Roberts and Tiwari (2017) & Working paper & 6 & 1.78 \\
\hline Ali et al. (2015a) & Journal of Development Studies & 2 & 0.59 \\
\hline Ali et al. (2017) & Journal of Development Studies & 1 & 0.3 \\
\hline Allen and Arkolakis (2016) & Working paper & 1 & 0.3 \\
\hline Amor and Pfaff (2008) & Working paper & 1 & 0.3 \\
\hline Ansar, Flyvbjerg, Budzier and Lunn (2016) & Oxford Review of Economic Policy & 2 & 0.59 \\
\hline Arman, Manesh, and Izady (2015) & Asian Economic and Financial Review & 9 & 2.67 \\
\hline Asher and Novosad (2016) & Working paper & 5 & 1.48 \\
\hline Asturias, García-Santana, and Ramos (2018) & Journal of the European Economic Association & 4 & 1.19 \\
\hline Atack and Margo (2011) & The Journal of Transport and Land Use & 1 & 0.3 \\
\hline Banerjee et al. (2012) & MIT/NBER working paper & 4 & 1.19 \\
\hline Barber et al. (2014) & Biological Conservation & 1 & 0.3 \\
\hline Baum-Snow (2007) & The Quarterly Journal of Economics & 1 & 0.3 \\
\hline Baum-Snow (2010) & $\begin{array}{l}\text { American Economic Review: Papers \& } \\
\text { Proceedings }\end{array}$ & 4 & 1.19 \\
\hline Baum-Snow (2017) & Working paper & 2 & 0.59 \\
\hline Baum-Snow et al. (2016) & Working paper & 9 & 2.67 \\
\hline $\begin{array}{l}\text { Baum-Snow, Brandt, Henderson, Turner, and } \\
\text { Zhang (2017) }\end{array}$ & The Review of Economics and Statistics & 11 & 3.26 \\
\hline
\end{tabular}


TABLE A2 (Continued)

\begin{tabular}{|c|c|c|c|}
\hline Study & Publication & $N$ & Share (\%) \\
\hline Baum-Snow et al. (2018) & Journal of Urban Economics & 12 & 3.56 \\
\hline Bell and van Dillen (2014) & Land Economics & 1 & 0.3 \\
\hline $\begin{array}{l}\text { BenYishayet, Trichler, Runfola and Goodman } \\
\text { (2018) }\end{array}$ & Working paper & 1 & 0.3 \\
\hline Bird and Straub (2014) & World Bank working paper & 3 & 0.89 \\
\hline $\begin{array}{l}\text { Blankespoor, Bougna, Garduno-Rivera and Selod } \\
\text { (2018a) }\end{array}$ & World Bank working paper & 8 & 2.37 \\
\hline Blankespoor, Emran, Shilpi and Xu (2018b) & World Bank working paper & 3 & 0.89 \\
\hline Blyde (2012) & Working paper & 4 & 1.19 \\
\hline $\begin{array}{l}\text { Bogart, Alvarez-Palau, Dunn, Satchell and Taylor } \\
\text { (2017) }\end{array}$ & Working paper & 15 & 4.45 \\
\hline Buys, Deichmann and Wheeler (2010) & Journal of African Economies & 1 & 0.3 \\
\hline Cantos et al. (2005) & Transport Reviews & 9 & 2.67 \\
\hline Chandra and Thompson (2000) & Regional Science and Urban Economics & 3 & 0.9 \\
\hline Combes and Lafourcade (2002) & Working paper & 3 & 0.89 \\
\hline Conde (2008) & Working paper & 2 & 0.59 \\
\hline Coşar and Demir (2016) & Journal of Development Economics & 1 & 0.3 \\
\hline Cropper et al. (2001) & Land Economics & 1 & 0.3 \\
\hline Cuong (2011) & Asia-Pacific Development Journal & 4 & 1.19 \\
\hline Damania and Wheeler (2015) & World Bank Group & 7 & 2.08 \\
\hline Damania et al. (2017) & American Journal of Agricultural Economics & 3 & 0.89 \\
\hline Dan Bogart (2009) & Economic History Review & 1 & 0.3 \\
\hline Dasgupta and Wheeler (2016) & World Bank working paper & 3 & 0.89 \\
\hline Deininger and Minten (2002) & American Journal of Agricultural Economics & 1 & 0.3 \\
\hline $\begin{array}{l}\text { Dercon, Gilligan, Hoddinott and Woldehanna } \\
\text { (2008) }\end{array}$ & American Journal of Agricultural Economics & 2 & 0.59 \\
\hline Donaldson and Hornbeck (2016) & The Quarterly Journal of Economics & 2 & 0.59 \\
\hline Donaldson (2018) & American Economic Review & 2 & 0.59 \\
\hline Dorosh, Wang, You and Schmidt (2012) & Agricultural Economics & 5 & 1.48 \\
\hline Duranton and Morrow (2013) & The Review of Economic Studies & 4 & 1.19 \\
\hline Duranton (2015) & Economics of Transportation & 2 & 0.59 \\
\hline Elshahawany, Haddad and Lahr (2015) & Working paper: Rutgers University & 5 & 1.48 \\
\hline Emran and Hou (2013) & The Review of Economics and Statistics & 8 & 2.37 \\
\hline Faber (2014) & Review of Economic Studies & 1 & 0.3 \\
\hline Fan and Chan-Kang (2008) & Transport Policy & 6 & 1.78 \\
\hline Fretz, Parchet and Robert-Nicoud (2017) & Working paper & 3 & 0.89 \\
\hline Frye (2016) & Working paper & 11 & 3.26 \\
\hline Gachassin (2013) & Journal of African Economies & 3 & 0.89 \\
\hline Garcia-Lopez, Holl and Viladecans-Marsal (2015) & Journal of Urban Economics & 2 & 0.59 \\
\hline Gertler et al. (2014) & Working paper & 2 & 0.59 \\
\hline
\end{tabular}


TABLE A2 (Continued)

\begin{tabular}{|c|c|c|c|}
\hline Study & Publication & $N$ & Share (\%) \\
\hline Ghani, Goswami and Kerr (2016) & The Economic Journal & 6 & 1.78 \\
\hline Ghani et al. (2016) & The World Bank Economic Review & 3 & 0.89 \\
\hline Gibbons et al. (2019) & Journal of Urban Economics & 1 & 0.3 \\
\hline Gibson and Rozelle (2003) & Economic Development and Cultural Change & 2 & 0.59 \\
\hline Gollin and Rogerson (2016) & Journal of Development Economics & 1 & 0.3 \\
\hline $\begin{array}{l}\text { Gonzalez-Navarro and Quintana-Domeque } \\
\text { (2013) }\end{array}$ & The Review of Economics and Statistics & 2 & 0.59 \\
\hline Haddad, Perobelli, Domingues and Aguiar (2011) & Journal of Development Effectiveness & 3 & 0.89 \\
\hline Haines and Margo (2008) & NBER Working Paper & 4 & 1.19 \\
\hline Herrendorf et al. (2012) & International Economic Review & 8 & 2.37 \\
\hline Huang and Xiong (2017) & Working paper & 2 & 0.59 \\
\hline Jedwab and Moradi (2015) & The Review of Economics and Statistics & 6 & 1.78 \\
\hline Jedwab and Storeygard (2017) & Working paper & 1 & 0.3 \\
\hline Khandker, Bakht and Koolwal (2009) & Economic Development and Cultural Change & 3 & 0.89 \\
\hline Khandker and Koolwal (2011) & World Bank working paper & 3 & 0.89 \\
\hline Khanna (2016) & Working paper & 1 & 0.3 \\
\hline Knaap and Oosterhaven (2011) & Research in Transportation Economics & 2 & 0.59 \\
\hline Lall, Wang and Deichmann (2010) & Working paper: UNU-WIDER & 2 & 0.59 \\
\hline $\begin{array}{l}\text { Li, De Pinto, Ulimwengu, You and Robertson } \\
\text { (2015) }\end{array}$ & Environmental and Resource Economics & 6 & 1.78 \\
\hline Li, Wen and Jiang (2017) & $\begin{array}{l}\text { International Journal of e-Navigation and } \\
\text { Maritime Economy }\end{array}$ & 2 & 0.59 \\
\hline Limao and Venables (2001) & The World Bank Economic Review & 2 & 0.59 \\
\hline $\operatorname{Lin}(2017)$ & Journal of Urban Economics & 6 & 1.78 \\
\hline Volpe Martincus and Blyde (2013) & Journal of International Economics & 1 & 0.3 \\
\hline Martincus et al. (2016) & Journal of Development Economics & 3 & 0.89 \\
\hline Michaels (2008) & The Review of Economics and Statistics & 3 & 0.89 \\
\hline Montolio and Sole-Olle (2007) & Papers in Regional Science & 1 & 0.3 \\
\hline Moreira, Volpe, Blyde and Rodriguez (2013) & $\begin{array}{l}\text { Inter-American Development Bank working } \\
\text { paper }\end{array}$ & 3 & 0.89 \\
\hline Morten and Oliveira (2017) & Working paper & 3 & 0.89 \\
\hline Pereira et al. (2014) & Working paper & 1 & 0.3 \\
\hline Perez-Cervantes (2014) & Bank of Mexico Working paper & 2 & 0.59 \\
\hline Pfaff et al. (2007) & Journal of Regional Science & 1 & 0.3 \\
\hline Roberts et al. (2012) & Regional Science and Urban Economics & 4 & 1.19 \\
\hline Rothenberg (2011) & Working Paper & 4 & 1.19 \\
\hline Sengupta, Coondoo and Rout (2016) & Journal of Development Policy and Practice & 5 & 1.48 \\
\hline Shiferaw, Soederbom, Siba and Alemu (2015) & The Journal of Development Studies & 2 & 0.59 \\
\hline Storeygard (2016) & The Review of Economic Studies & 2 & 0.59 \\
\hline $\begin{array}{l}\text { van der Weide, Rijkers, Blankespoor and } \\
\text { Abrahams (2018) }\end{array}$ & World Bank working paper & 4 & 1.19 \\
\hline
\end{tabular}


TABLE A2 (Continued)

\begin{tabular}{llll}
\hline Study & Publication & S & Share (\%) \\
Wang and Wu (2015) & Economic Development and Cultural Change & 4 & 1.19 \\
\hline Wang and Charles (2010) & Working paper & 6 & 1.78 \\
Weinhold and Reis (2008) & Global Environmental Change & 1 & 0.3 \\
Xu and Nakajima (2015) & Papers in Regional Science & 5 & 1.48 \\
\hline
\end{tabular}

Note: $\mathrm{N}$ refers to the number of results from the paper that are included in the sample.

TABLE A3 Numbers of results, studies, and countries included in the meta-analysis by region

\begin{tabular}{|c|c|c|c|c|}
\hline Region & \# results & \# studies & \# countries & List of countries \\
\hline North America & 30 & 8 & 2 & Mexico, US \\
\hline Africa & 29 & 12 & $11+$ & $\begin{array}{l}\text { Cameroon, Central African Republic, DRC, East- } \\
\text { Africa, Ethiopia, Ghana, Nigeria, Tanzania, West- } \\
\text { Africa }\end{array}$ \\
\hline East Asia Pacific (EAP) & 62 & 17 & 5 & $\begin{array}{l}\text { China, Indonesia, Myanmar, Papua New Guinea, } \\
\text { Vietnam }\end{array}$ \\
\hline Western Europe & 10 & 5 & 5 & France, Germany, Spain, Switzerland, UK \\
\hline $\begin{array}{l}\text { Latin American and } \\
\text { Caribbean (LAC) }\end{array}$ & 8 & 7 & 3 & Bolivia, Brazil, Peru \\
\hline $\begin{array}{l}\text { Middle East and North } \\
\text { Africa (MENA) }\end{array}$ & 5 & 2 & 1 & West Bank and Gaza \\
\hline South Asia (SAR) & 32 & 13 & 3 & Bangladesh, India, Thailand \\
\hline Total & 176 & 55 & & \\
\hline
\end{tabular}

\section{APPENDIX B: ADDITIONAL META-ANALYSIS RESULTS AND ROBUSTNESS TESTS}

\section{B1. Kernal densities of outcome estimate coefficients and t statistics \\ B2. Ordered-probit estimation and marginal effects results}

\section{B3. OLS and random effects model estimation results}

\section{Dealing with extreme coefficients}

Extreme deviations from the main sample of estimates (in our case given by the $t$ statistic for the estimated coefficient on the treatment variable) are problematic for statistical analyses. They usually compress the variation of the rest of the sample. To deal with this issue, we use the Grubbs test (NIST/SEMATECH, 2006) as our criterion to exclude extreme outliers from our estimation. This test calculates, $G$, the maximum deviation from the sample mean, divided by the standard deviation (SD), calculated including that observation. If $G=\max \left(X_{i}-\bar{X} / S D\right)>G^{*}$, the observation is deleted. $G^{*}$ is the critical value for $G$ at a confidence level $\alpha$ and is computed by $G^{*}=(N-1) \sqrt{T^{2} / N\left(N-2+T^{2}\right)}$, where $T$ is the critical value of a $t$ distribution with $(N-2)$ degrees of freedom and a confidence interval of $\alpha / 2 N$. We start with $N=209$ observations (estimated coefficients) and set $\alpha=0.001$, which yields $G^{*}=5.4255$. The Grubbs procedure eliminates one outlier at a time, recalculating $\bar{X}$ and SD with each iteration. We apply this procedure, and this led to the removal of the 
(a)

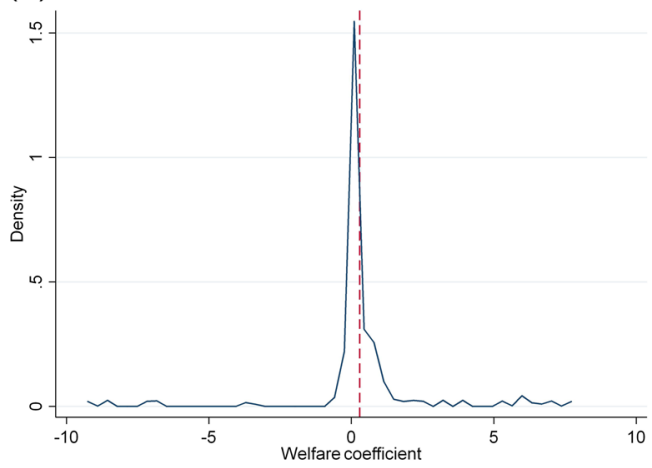

(c)

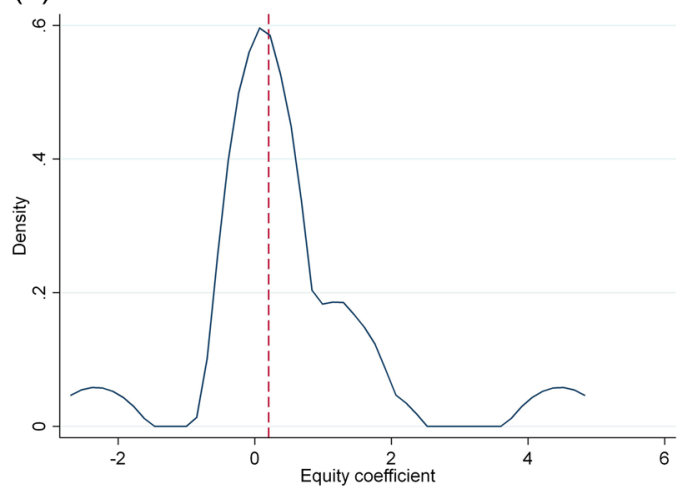

(b)

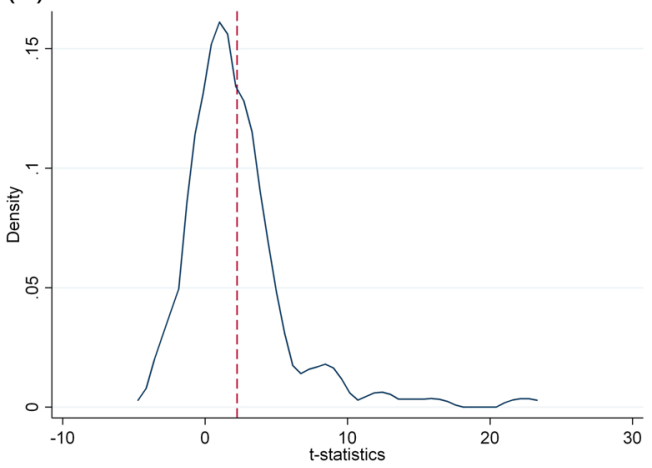

(d)

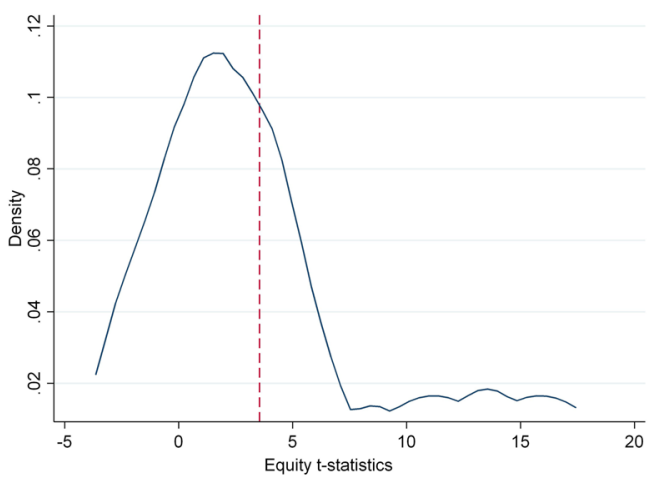

FIGURE B 1 Estimated kernel densities of the estimated coefficients and $t$ statistics. The dashed vertical line marks the mean of the distributions

coefficients of 14 outliers. As a result, the mean and standard deviation changed from 0.127 to 0.19 and from 1.79 to 0.63 , respectively.

As can be seen from Table B2, there is a large amount of variance in the estimated coefficient for the transportation effects. The fifth percentile is -0.37 and the 95 th percentile is 1.64 . The standard deviation is 0.63 and the interquartile range is 0.28 . As can be seen from panel (a) of Figure 16 , the vertical line shows that the mean is positive, which is consistent with the descriptive section where the typical paper finds a beneficial and significant impact.

\section{Testing for sampling error}

Our coefficients of transportation infrastructure impact are based on a sample of studies that cover different countries and sample-periods and which were published in different years. It is therefore important to investigate the role of sampling error. To do so, we estimate the $I^{2}$ statistic provided by Higgins et al. (2003). The $I^{2}$ tests for the variation in the impact coefficient attributable to heterogeneity. Specifically, let $\beta_{i}$ represent an individual estimate of the transportation impact and $\bar{\beta}$ represent an estimate of the population mean.

Define $Z_{i}$ by:

$$
Z_{i}=\frac{\beta_{i}-\bar{\beta}}{\sigma\left(\beta_{i}\right)}
$$


(a)

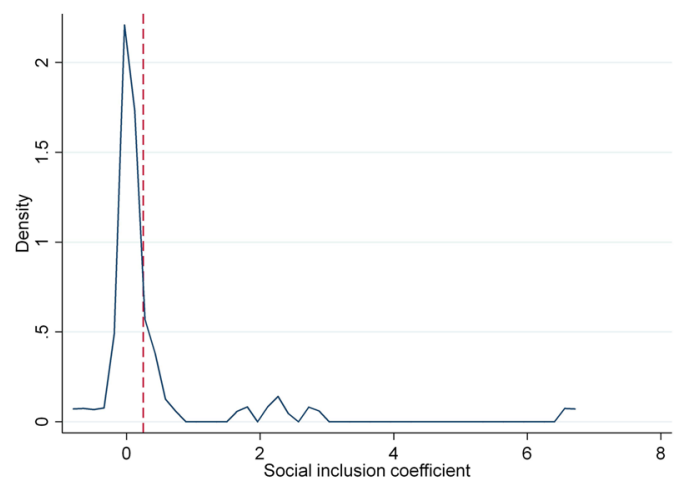

(c)

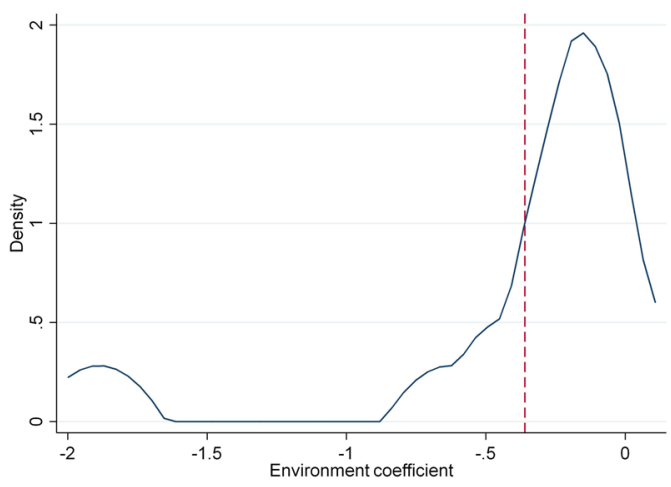

(b)

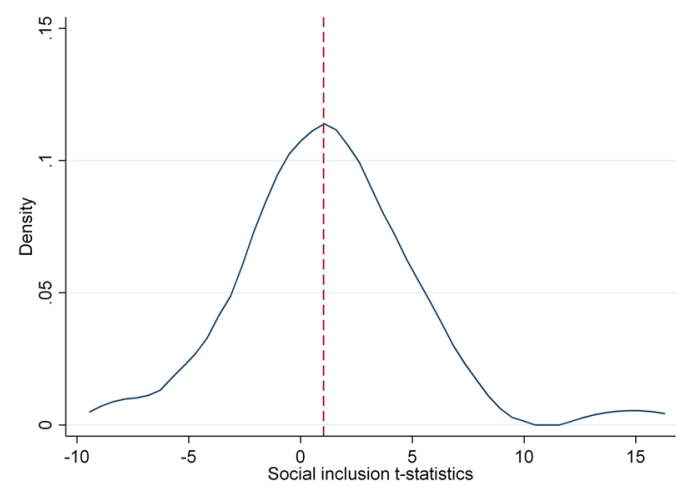

(d)

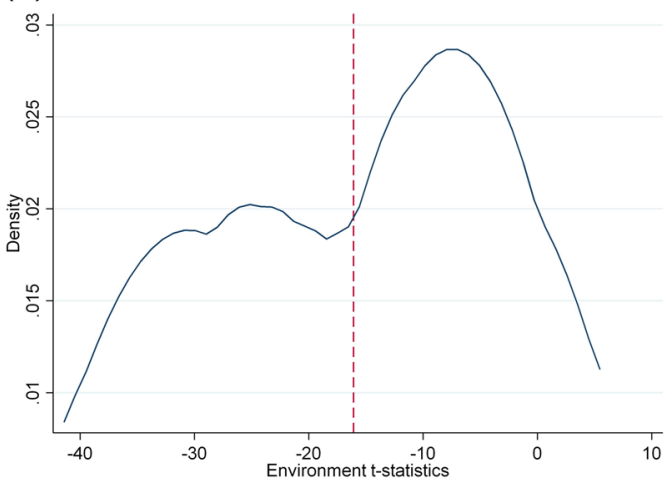

FIGURE B 2 Estimated kernel densities of the estimated coefficients. The dashed vertical line marks the mean of the distributions

Under the null of a single population mean, $Z_{i}$ in Equation (A1) should follow a $t$ distribution with $n_{i}-k_{i}$ degrees of freedom. The estimated $I^{2}$ statistic is $98 \%$ and represents the percentage of between-results variability due to heterogeneity. This statistic points toward a strong indication of heterogeneity $(97.9 \%$ of the total variation across our studies is due to heterogeneity rather than chance). Based on this statistically significant heterogeneity result, we investigate the causes of between-paper variation (heterogeneity) in the transportation impact estimation. This result is also confirmed by the Galbraith funnel plot of the transport estimates with the precision of their estimation. In the absence of heterogeneity, much of the within area is above \pm 2 .

\section{Testing for publication bias and small-study effect}

Publication bias has long been a major concern for meta-analysts. Compared to studies that find small and insignificant effects, studies that find statistically and significant results are more likely to be published because they are more likely to be well received by researchers, reviewers, and editors. To perform a test of publication effects, we employ the commonly used Egger test. This test regresses the standard normal deviate of a study effect estimate against its standard error. The test null is that there are no small-study effects. The estimated bias coefficient is 1.269 with a standard error of 0.429 , giving a $p$ value of 0.003 . A failure to reject the null hypothesis suggests that there are no small-study effects, that is, estimates that are published in journals tend to emphasize small effects. 


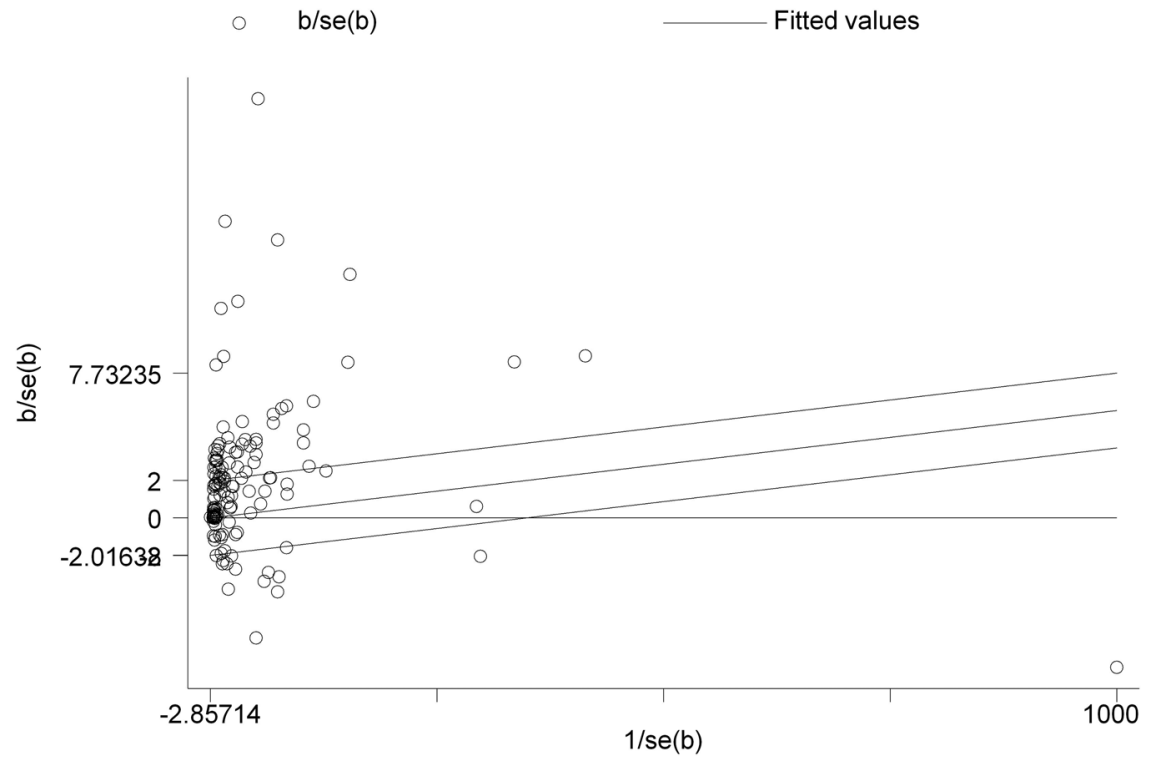

FIGURE B 3 Assessing heterogeneity using the Galbraith plot. Source: Authors computation based on Galbraith plot 


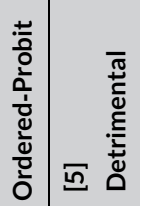

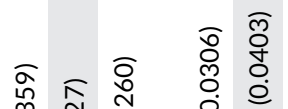

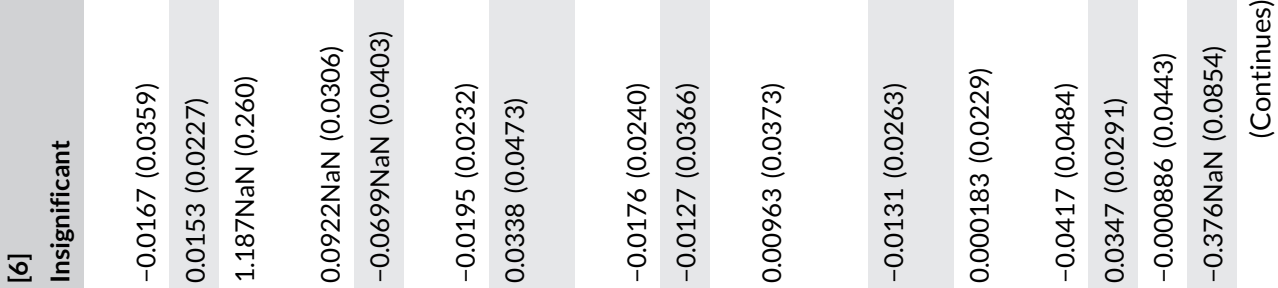

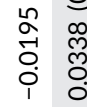

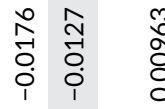

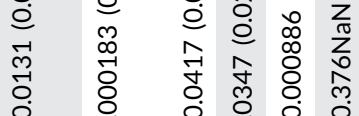

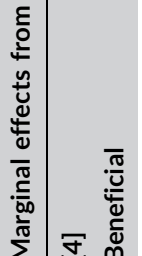

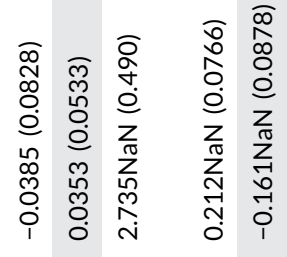

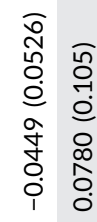

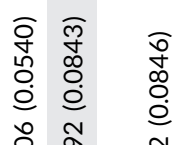

ơ

สิ

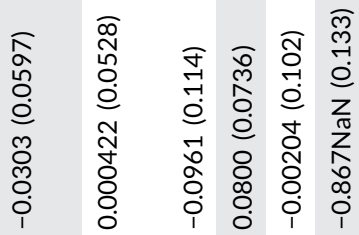

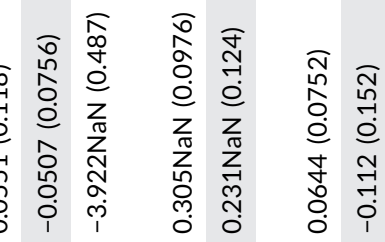

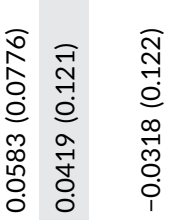

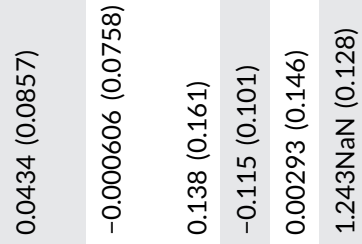

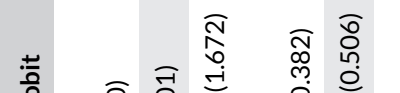

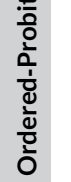

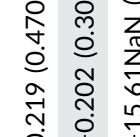

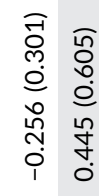

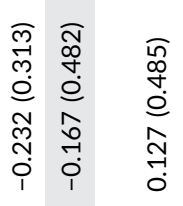

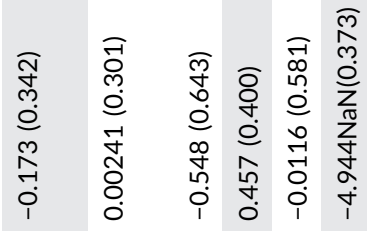

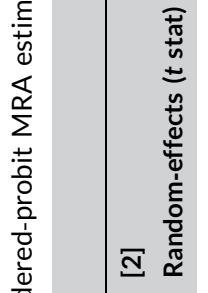

焉

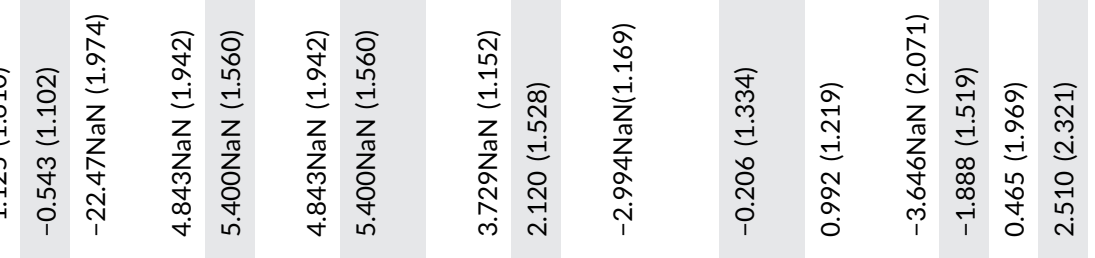

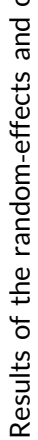

늘

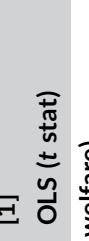

制

1

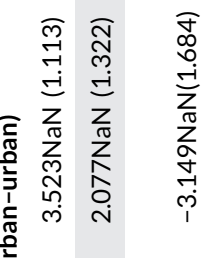

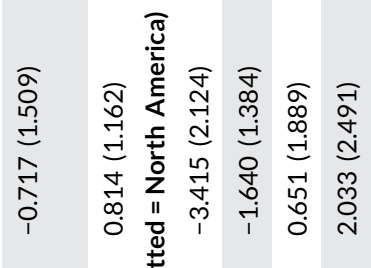

更

도

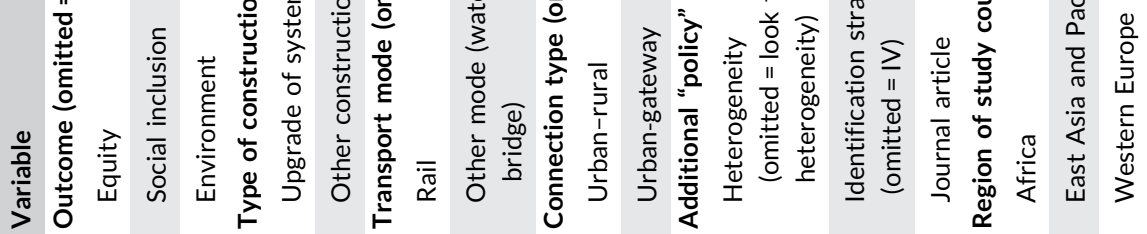




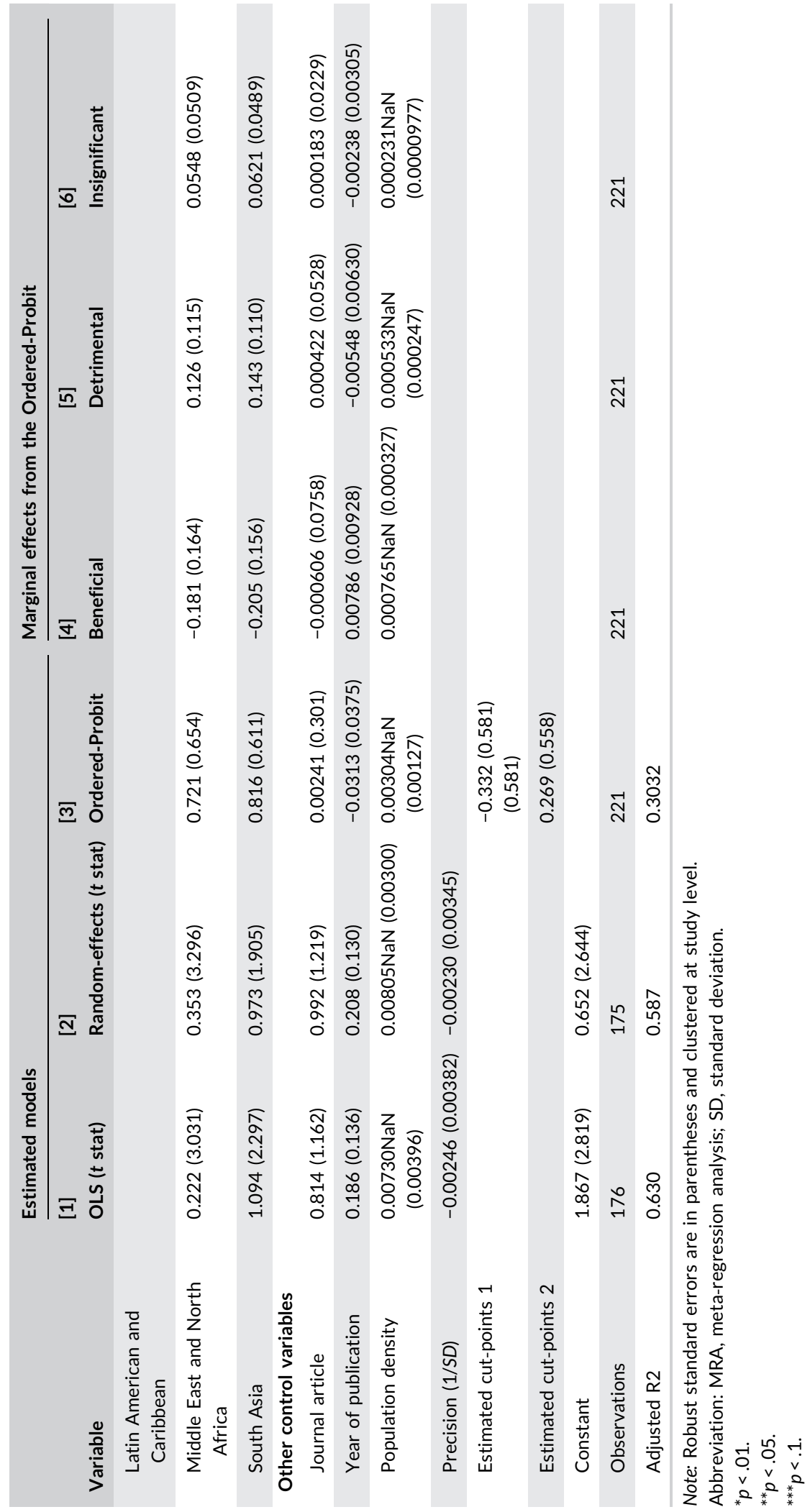


TABLE B2 The Grubbs procedure to eliminate extreme coefficients

\begin{tabular}{lllllllll} 
Coefficient & $N$ & Mean & SD & IQR & P5 & P95 & Min & Max \\
\hline Before & 209 & 0.27 & 1.79 & 0.31 & -0.63 & 2.77 & -9.14 & 7.61 \\
After & 195 & 0.19 & 0.63 & 0.28 & -0.37 & 1.64 & -2.22 & 3.22 \\
\hline
\end{tabular}

Note: $I Q R=Q_{3}-Q_{1} ; p 5=5$ th percentile; $p 95=95$ th percentile.

Abbreviations: IQR = interquartile range; $\min =$ minimum; $\max =$ maximum; $\mathrm{SD}=$ standard deviation. 